\title{
Fermentation in cyanobacteria1
}

Stal, L.J.; Moezelaar, H.R.

Publication date

1997

Published in

FEMS Microbiology Reviews

Link to publication

Citation for published version (APA):

Stal, L. J., \& Moezelaar, H. R. (1997). Fermentation in cyanobacteria1. FEMS Microbiology Reviews, (21), 179-211.

\section{General rights}

It is not permitted to download or to forward/distribute the text or part of it without the consent of the author(s) and/or copyright holder(s), other than for strictly personal, individual use, unless the work is under an open content license (like Creative Commons).

\section{Disclaimer/Complaints regulations}

If you believe that digital publication of certain material infringes any of your rights or (privacy) interests, please let the Library know, stating your reasons. In case of a legitimate complaint, the Library will make the material inaccessible and/or remove it from the website. Please Ask the Library: https://uba.uva.nl/en/contact, or a lette to: Library of the University of Amsterdam, Secretariat, Singel 425, 1012 WP Amsterdam, The Netherlands. Yo will be contacted as soon as possible. 


\title{
Fermentation in cyanobacteria ${ }^{1}$
}

\author{
Lucas J. Stal ${ }^{\mathrm{a}, *}$, Roy Moezelaar ${ }^{\mathrm{b}}$ \\ ${ }^{a}$ Netherlands Institute of Ecology, Centre for Estuarine and Coastal Ecology, P.O. Box 140, NL-4400 AC Yerseke, The Netherlands \\ b Agrotechnological Research Institute (ATO-DLO), P.O. Box 17, NL-6700 AA Wageningen, The Netherlands
}

Received 24 April 1997; revised 1 August 1997; accepted 2 August 1997

\begin{abstract}
Although cyanobacteria are oxygenic phototrophic organisms, they often thrive in environments that become periodically anoxic. This is particularly the case in the dark when photosynthetic oxygen evolution does not take place. Whereas cyanobacteria generally utilize endogenous storage carbohydrate by aerobic respiration, they must use alternative ways for energy generation under dark anoxic conditions. This aspect of metabolism of cyanobacteria has received little attention but nevertheless in recent years a steadily increasing number of publications have reported the capacity of fermentation in cyanobacteria. This review summarizes these reports and gives a critical consideration of the energetics of dark fermentation in a number of species. There are a variety of different fermentation pathways in cyanobacteria. These include homo- and heterolactic acid fermentation, mixed acid fermentation and homoacetate fermentation. Products of fermentation include $\mathrm{CO}_{2}$, $\mathrm{H}_{2}$, formate, acetate, lactate and ethanol. In all species investigated, fermentation is constitutive. All enzymes of the fermentative pathways are present in photoautotrophically grown cells. Many cyanobacteria are also capable of using elemental sulfur as electron acceptor. In most cases it seems unlikely that sulfur respiration occurs. The main advantage of sulfur reduction seems to be the higher yield of ATP which can be achieved during fermentation. Besides oxygen and elemental sulfur no other electron acceptors for chemotrophic metabolism are known so far in cyanobacteria. Calculations show that the yield of ATP during fermentation, although it is low relative to aerobic respiration, exceeds the amount that is likely to be required for maintenance, which appears to be very low in these cyanobacteria. The possibility of a limited amount of biosynthesis during anaerobic dark metabolism is discussed.
\end{abstract}

Keywords: Fermentation; Cyanobacteria; Dark metabolism; Embden-Meyerhof-Parnas pathway; Lactate dehydrogenase; Lactate fermentation; Mixed acid fermentation; Sulfur reduction

\section{Contents}

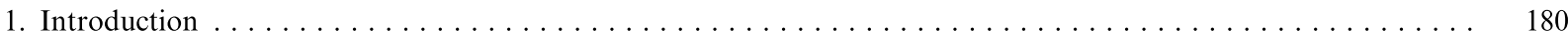

2. Occurrence of dark anoxic conditions in cyanobacterial communities $\ldots \ldots \ldots 182$

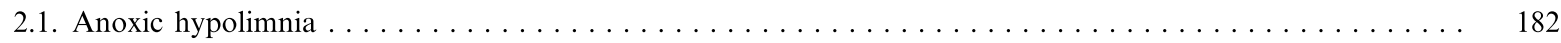

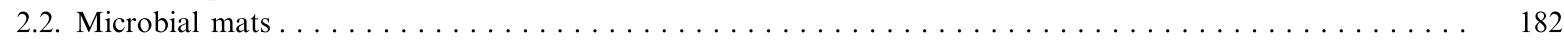

* Corresponding author. Tel.: +31 (113) 577497; Fax: +31 (113) 573616; e-mail: stal@cemo.nioo.knaw.nl

${ }^{1}$ Publication 2274 of the Centre of Estuarine and Coastal Ecology, Yerseke, The Netherlands.

0168-6445/97/\$32.00 (C) 1997 Federation of European Microbiological Societies. Published by Elsevier Science B.V.

PII S $0168-6445(97) 00056-9$ 


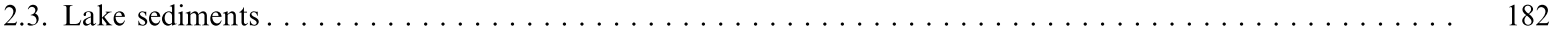

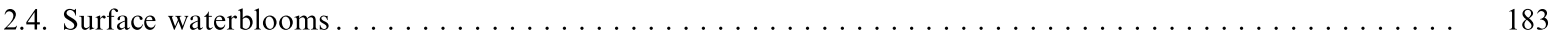

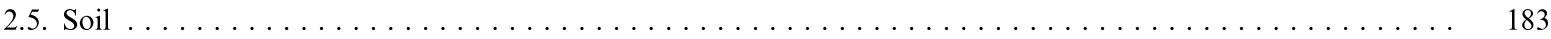

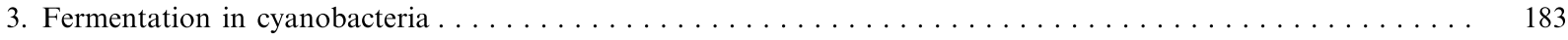

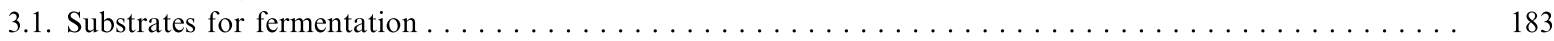

3.2. Fermentation products and the diversity of fermentation pathways $\ldots \ldots \ldots 184$

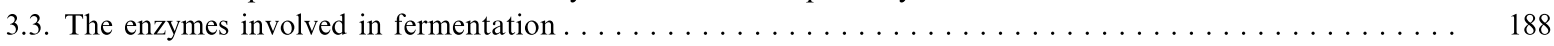

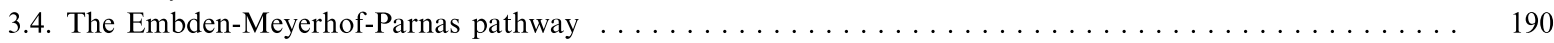

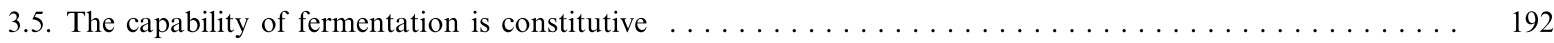

4. Lactate dehydrogenase and lactate production in cyanobacteria $\ldots \ldots \ldots 193$

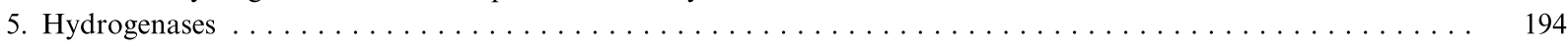

6. Electron acceptors and anaerobic respiration $\ldots \ldots \ldots \ldots \ldots$

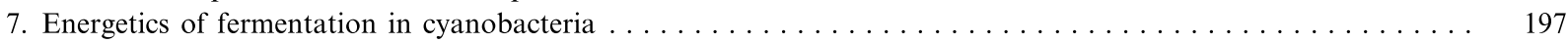

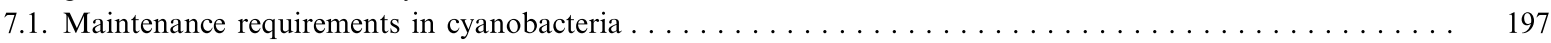

7.2. Energetics of fermentation in Oscillatoria limnetica $\ldots \ldots \ldots \ldots \ldots$

7.3. Energetics of fermentation in Oscillatoria limosa $\ldots \ldots \ldots \ldots \ldots$

7.4. Energetics of fermentation in Microcystis aeruginosa $\ldots \ldots \ldots \ldots \ldots$

7.5. Energetics of fermentation in Microcoleus chthonoplastes $\ldots \ldots \ldots 201$

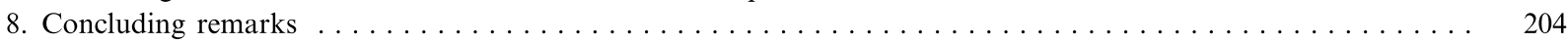

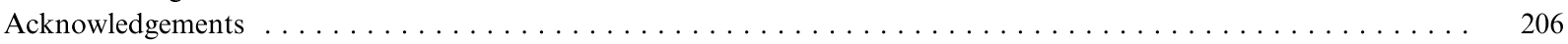

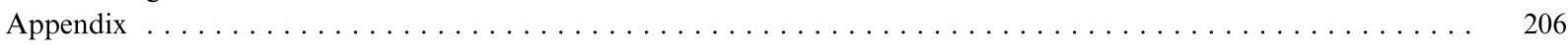

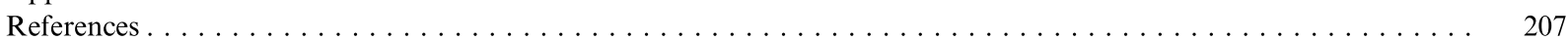

\section{Introduction}

The cyanobacteria constitute one of the largest groups of prokaryotes. Encompassing a wide diversity in morphology, physiology, cell division patterns, cell differentiation, and habitats, the cyanobacteria are unified by the ability to carry out a plantlike oxygenic photosynthesis using water as electron donor and the possession of chlorophyll $a$ and phycobiliproteins as photosynthetic pigments. In addition, all cyanobacteria are capable of using $\mathrm{CO}_{2}$ as the sole carbon source, employing the reductive pentose phosphate pathway or Calvin cycle [1]. Many species can fix molecular nitrogen [2].

In nature, most cyanobacteria face a regular cycle of day and night. In addition, darkness may occur as a result of self-shadowing in dense planktonic and benthic communities, sedimentation in aquatic systems, and sediment deposition on benthic communities. Certain symbiotic cyanobacteria that live in the rhizosphere of plants seem to thrive permanently in the dark [3]. In order to meet the energy demands in the dark for maintenance and the possibility of some growth, cyanobacteria have to resort to a chemotrophic mode of energy generation. In most species, glycogen accumulated during photoautotrophic growth serves as the energy source in the dark [1]. Glucose residues from glycogen are degraded via the oxidative pentose phosphate pathway and metabolic energy is generated by respiration with oxygen as electron acceptor [4]. It was demonstrated that the planktonic cyanobacterium Oscillatoria agardhii is able to maintain growth in the dark at the same rate as in the light when cultivated under a lightdark regime indicating that part of the glycogen is used as carbon source for synthesis of cell constituents [5-7].

In addition to oxygenic photoautotrophy and dark respiration of glycogen, cyanobacteria display alternative modes of energy generation and growth. More than half of the species tested so far are facultative photoheterotrophs [1,8]. Photoheterotrophic cyanobacteria are capable of taking up a limited number of organic compounds and assimilate them but need light as energy source. Only a relatively small number of species are able to grow chemoorganotrophically in the dark at the expense of a limited number of organic compounds, predominantly glucose, fructose, or sucrose (Table 1). In most of these cases chemoorganotrophic growth was observed only under aerobic conditions. Anaerobic chemoorganotrophic growth was reported in Nostoc sp. [24] and 
Table 1

Dark chemoorganotrophic growth of cyanobacteria ${ }^{a}$

\begin{tabular}{|c|c|c|c|c|}
\hline Strain & Condition & Substrate & Doubling & Ref. \\
\hline Anabaena azollae AaN & anaerobic & glucose, fructose & & {$[10]$} \\
\hline Anabaenopsis circularis & aerobic & glucose, fructose, sucrose, maltose & & {$[12]$} \\
\hline Aphanocapsa sp. 6702 & aerobic & glucose & & {$[13]$} \\
\hline Aphanocapsa sp. 6805 & aerobic & glucose & & [13] \\
\hline Calothrix marchica & aerobic & sucrose & & [9] \\
\hline Chlorogloeopsis fritschii (Chlorogloea) & aerobic & $\begin{array}{l}\text { sucrose, acetate, mannitol, glucose, maltose, } \\
\text { glycine, glutamine }\end{array}$ & $144 \mathrm{~h}$ & [16-19] \\
\hline Chlorogloeopsis sp. 6912 & aerobic & sucrose & $80 \mathrm{~h}$ & {$[20]$} \\
\hline Fremyella diplosiphon & aerobic & glucose & & {$[21]$} \\
\hline Nostoc MAC & aerobic & glucose, fructose, sucrose & & {$[25-27]$} \\
\hline Nostoc sp. $\mathrm{Al} 2$ & anaerobic & glucose, fructose & & {$[10]$} \\
\hline Oscillatoria agardhii & aerobic & endogenous glycogen & & {$[6,7]$} \\
\hline Oscillatoria terebriformis & anaerobic & glucose, fructose & $10 \mathrm{~d}$ & {$[28]$} \\
\hline Phormidium luridum & aerobic & sucrose & & [29] \\
\hline Plectonema boryanum & aerobic & $\begin{array}{l}\text { glucose, fructose, sucrose, ribose, maltose, } \\
\text { mannitol }\end{array}$ & $49 \mathrm{~h}-13 \mathrm{~d}$ & {$[29-32]$} \\
\hline Plectonema calothrioides & aerobic & sucrose & & {$[14,15]$} \\
\hline Scytonema schmidlei & aerobic & sucrose & & [9] \\
\hline Spirulina platensis & aerobic & & & {$[33,34]$} \\
\hline Synechocystis sp. 6714 & aerobic & glucose & $50-60 \mathrm{~h}$ & {$[13,18,20,27]$} \\
\hline
\end{tabular}

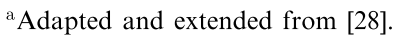

Oscillatoria terebriformis [28]. Moezelaar and Stal [22] reported anaerobic decomposition of exogenous glucose in Microcystis aeruginosa and recently obtained evidence for the occurrence of some growth [37]. With a few exceptions chemoorganotrophic growth of cyanobacteria on external substrates is much slower than under photoautotrophic conditions. This is probably because the uptake of the substrate is limiting. As mentioned above, O. agardhii is able to maintain its growth rate in the dark at the same value as in the light, but only at the expense of endogenous storage carbohydrate which will last for a limited period $[6,7]$.

Whereas cyanobacteria and eukaryotic microalgae normally display aerobic respiratory metabolism during the dark, anoxygenic phototrophic bacteria generally face anoxic conditions. In order to be able to generate energy in the dark these bacteria must be able to carry out fermentation. This has been shown for instance in the anoxygenic non-sulfur purple bacterium Rhodospirillum rubrum [38,39]. Other species can not grow unless an electron acceptor such as dimethylsulfoxide [40] or trimethylamine$N$-oxide [41] are present. A very efficient mode of anaerobic dark metabolism has been demonstrated in the anoxygenic phototrophic bacterium Chromatium vinosum. This species has been shown to convert glycogen into poly- $\beta$-hydroxybutyrate, using elemental sulfur as electron acceptor [42]. This metabolism results only in a minor loss of storage carbon but 
allows substrate level phosphorylation. In the light, sulfide is oxidized photosynthetically to elemental sulfur which is stored intracellularly in these bacteria and may subsequently serve as electron acceptor during the dark. Theoretically this sulfur reduction could be associated with an electron transport chain and yield additional energy. It is not known whether this organism is capable of growth anaerobically in the dark at the expense of endogenous carbohydrate.

Cyanobacteria can also be found in environments which are periodically anoxic. In the light when sulfide is present, several species may switch to anoxygenic mode of photosynthesis using sulfide as electron donor [43] while in the dark fermentation of endogenous glycogen storage and reduction of elemental sulfur occurs in order to sustain the energy requirements of these cyanobacteria [44].

Fermentation of endogenous storage material has also been observed in green microalgae such as Chlorella fusca, Chlamydomonas reinhardii and Chlorogonium elongatum, which produce formate, acetate and ethanol as fermentation products $[45,46]$. Not much information is available on the pathways and regulation of fermentation in these eukaryotic algae, which is in part due to the complex interactions of different compartmentalized pathways in these organisms.

Dark anaerobic metabolism in cyanobacteria has received little attention. There is a steadily increasing number of publications that report the capacity of fermentation in cyanobacteria and this review attempts to summarize these reports and give a critical evaluation of fermentative energy generation.

\section{Occurrence of dark anoxic conditions in cyanobacterial communities}

Mainly because of their oxygen-evolving photosynthesis, cyanobacteria are usually associated with aerobic environments, and, consequently, research of dark energy generation has focused on aerobic metabolism. However, this has not recognized the fact that many cyanobacteria are found in environments that are permanently anoxic or become anoxic in the dark. The following sections give some examples of such anoxic environments in which cyanobacteria thrive.

\subsection{Anoxic hypolimnia}

One example of an anoxic hypolimnion environment inhabited by cyanobacteria is Solar Lake, a hypersaline pond on the shore of the Sinai desert. This lake displays a typical annual cycle of mixing. After a short period of holomixis in summer, stratification builds up in September and lasts until July [47]. During the period of stratification, a cyanobacterial bloom consisting of Oscillatoria sp. and Microcoleus sp. develops in the anoxic sulfide-rich hypolimnion which merges into a flocculant mat [48]. The dominant organism of this bloom, $O$. limnetica, is capable of anoxygenic photosynthesis, using sulfide as the electron donor, oxidizing it to elemental sulfur which accumulates extracellularly [49]. In the dark, energy is generated by anaerobic respiration of glycogen using sulfur as electron acceptor [44]. Alternatively, this organism may ferment glycogen to lactate.

\subsection{Microbial mats}

Microbial mats are a typical example of an environment which experiences periodically anoxic conditions. The majority of microbial mats are composed of cyanobacteria as the dominant group of microorganisms [50]. These laminated sediment ecosystems are ubiquitous in a variety of different environments such as hot spring effluents, intertidal coastal sediments, and hypersaline ponds. Microbial mats are characterized by marked daily fluctuations of oxygen concentration that can be attributed to the physiology of the cyanobacteria. During the daytime oxygenic photosynthesis by these organisms results in oxygen supersaturation. In the dark cyanobacteria will switch to respiration, but due to the high oxygen demand, diffusion of oxygen into the mat is usually insufficient to cover the demands and as a result the mat will turn anoxic [51].

\subsection{Lake sediments}

The annual life cycle of planktonic cyanobacteria in lakes at temperate climate zones involves a phase of perennation in the sediment, where the organisms accumulate during and after bloom formation. Species belonging to the order of the Nostocales such as 
Anabaena and Aphanizomenon survive as akinetes, resting stages that differentiate from vegetative cells during blooming [52]. Species of the genus Microcystis, however, do not form such morphologically distinct resting stages, but survive as colonies of vegetative cells in the sediment. In most cases the bottom sediments of lakes are permanently in darkness and anoxic. Under these conditions Microcystis is able to maintain cellular integrity and retains the capacity of photosynthesis [53,54]. Although the cells also retain their gas vacuoles, the colonies are not buoyant. The population in the sediment serves as viable stock for re-establishment of a planktonic population the following year.

\subsection{Surface waterblooms}

The eutrophic state of many lakes and water reservoirs often results in the mass development of planktonic cyanobacteria, very often species belonging to the genera Anabaena, Aphanizomenon, Microcystis, or Nodularia. These genera are characterized by a colonial organization and the possession of gas vacuoles, hollow proteinaceous vesicles that provide the cells with buoyancy. Thus, when the water column is stable, the colonies will accumulate at the water surface and form surface waterblooms [55]. The wind blowing across the water surface may concentrate the colonies into dense scums on the leeward shore. Like microbial mats, such scums become anoxic at night [56]. The attenuation of light may be so high that even in the daytime cells in the deeper layers of thick scums experience dark anoxic conditions.

\subsection{Soil}

Several species of the $\mathrm{N}_{2}$-fixing genus Nostoc develop in symbiotic association with cycads, allowing them to use molecular nitrogen as the $N$ source [57]. They are found in a mucilage-filled space in the outer cortex of the coralloid roots where they live in permanent darkness up to $50 \mathrm{~cm}$ below the soil surface. As a consequence, photosynthesis is not possible and the cyanobacteria grow chemoorganotrophically at the expense of an organic substrate as carbon and energy source supplied by the host [58]. In the coralloid roots anoxia may occur after heavy rains when diffusion of oxygen into the soil is reduced by stagnant water.

\section{Fermentation in cyanobacteria}

The occurrence and survival of cyanobacteria in environments that are permanently anoxic or become anoxic at night implies the capability of anaerobic dark energy generation. Species from such environments have been shown to be capable of fermentation at the expense of intracellular carbohydrates [59]. Table 2 gives a list of cyanobacteria that are capable of fermentation.

\subsection{Substrates for fermentation}

Most of the studies on dark anaerobic energy generation in cyanobacteria have only considered the use of endogenous carbohydrates as substrate. $O$. limnetica is not capable of using exogenous glucose as substrate for fermentation [44]. Thus far, fermentation at the expense of exogenous substrates has been described for a few species only. These include Nostoc sp. [24], O. terebriformis [28], M. aeruginosa [22] and a number of symbiotic species [10]. In addition to endogenous carbohydrates, the Cycad symbiont Nostoc sp. strain Cc also degrades exogenous glucose according to a homoacetic fermentation [62]. The use of glucose as substrate for fermentation allows the organism to prolong dark anaerobic survival considerably. The chemoorganotrophic capacities of cyanobacteria are limited and seem to be predominantly restricted to species occurring symbiotically. The concentrations of substrate necessary to support anaerobic chemoorganotrophic growth in cyanobacteria are high $(5-30 \mathrm{mM})$ and are not likely to be encountered by free-living organisms.

The majority of the cyanobacteria is regarded as obligately photoautotrophic [1]. In the light, these species accumulate glycogen which serves as energy source in the dark. In addition, marine cyanobacteria may use their osmoprotectant as substrate during fermentation, as has been shown for $O$. limosa [63] and Microcoleus chthonoplastes [61]. Remarkably, $M$. chthonoplastes, which accumulates glucosylglycerol as osmoprotectant [66], ferments only the glucose residue, whereas the glycerol residue is excreted. 
Table 2

Cyanobacteria capable of fermentation

\begin{tabular}{|c|c|c|c|c|}
\hline Organism & Strain, origin & Fermentation pathway & Products $^{\mathrm{a}}$ & Ref. \\
\hline Anabaena azollae AaL & symbiont from Azolla caroliniana & homoacetate & acetate (lactate, $\mathrm{CO}_{2}, \mathrm{H}_{2}$ ) & {$[10]$} \\
\hline Anabaena azollae AaN & symbiont from Azolla caroliniana & homoacetate & acetate (lactate, $\mathrm{CO}_{2}, \mathrm{H}_{2}$ ) & {$[10]$} \\
\hline Anabaena azollae AaS & symbiont from Azolla filiculoides & homoacetate & acetate (lactate, $\mathrm{CO}_{2}, \mathrm{H}_{2}$ ) & {$[10]$} \\
\hline Anabaena siamensis As1 & paddy field & homoacetate & acetate $\left(\mathrm{CO}_{2}, \mathrm{H}_{2}\right)$ & {$[10]$} \\
\hline Cyanothece & PCC 7822 (Inst. Pasteur) & mixed acid & \multirow{2}{*}{\multicolumn{2}{|c|}{$\begin{array}{l}\mathrm{H}_{2} \text {, ethanol, lactate, formate, acetate [60] } \\
\mathrm{H}_{2} \text {, ethanol, lactate, formate, acetate [61] }\end{array}$}} \\
\hline Microcoleus chthonoplastes & microbial mat & mixed acid & & \\
\hline Microcystis aeruginosa & PCC 7806 (Inst. Pasteur) & mixed acid & \multicolumn{2}{|c|}{$\mathrm{H}_{2}$, ethanol, acetate } \\
\hline Nostoc sp. Cc & symbiont from Cycas circinalis & homoacetate & acetate (lactate, $\mathrm{CO}_{2}, \mathrm{H}_{2}$ ) & {$[10,62]$} \\
\hline Nostoc sp. $\mathrm{Al} 2$ & symbiont from Anthoceros laevis & homoacetate & acetate (lactate, $\mathrm{CO}_{2}, \mathrm{H}_{2}$ ) & {$[10]$} \\
\hline Nostoc sp. Ef1 & symbiont from Encephalartos ferox & homoacetate & acetate (lactate, $\mathrm{CO}_{2}, \mathrm{H}_{2}$ ) & {$[10]$} \\
\hline Nostoc sp. MAC & symbiont from Macrozamia lucida & homoacetate & acetate (lactate, $\mathrm{CO}_{2}, \mathrm{H}_{2}$ ) & {$[10]$} \\
\hline Nostoc sp. Mm1 & symbiont from Macrozamia moorei & homoacetate & acetate (lactate, $\mathrm{CO}_{2}, \mathrm{H}_{2}$ ) & {$[10]$} \\
\hline Nostoc sp. M1 & symbiont from Macrozamia sp. & homoacetate & acetate $\left(\mathrm{CO}_{2}, \mathrm{H}_{2}\right)$ & {$[10]$} \\
\hline Nostoc sp. Gm & symbiont from Gunnera manicata & homoacetate & acetate (lactate) & {$[10]$} \\
\hline Nostoc sp. T1 & paddy field & homoacetate & acetate (formate, $\mathrm{CO}_{2}, \mathrm{H}_{2}$ ) & {$[10]$} \\
\hline Nostoc sp. Bali & paddy field & homoacetate & acetate $\left(\mathrm{CO}_{2}, \mathrm{H}_{2}\right)$ & {$[10]$} \\
\hline Oscillatoria limnetica & hypolimnion Solar Lake & homolactate & lactate & {$[44]$} \\
\hline Oscillatoria limosa & microbial mat & heterolactate homoacetate & lactate, ethanol, acetate & {$[63]$} \\
\hline Oscillatoria sp. & microbial mat & not known & lactate, ethanol, acetate, formate & [64] \\
\hline Oscillatoria terebriformis & hot spring microbial mat & homolactate? & $?$ & {$[28]$} \\
\hline Spirulina platensis & not known & mixed acid & \multicolumn{2}{|c|}{$\mathrm{H}_{2}$, ethanol, acetate, formate, lactate [65] } \\
\hline Spirulina minosa & not known & not known & lactate, acetate & {$[64]$} \\
\hline
\end{tabular}

${ }^{a}$ Compounds in parentheses are produced in minor quantities.

Degradation of the osmoprotectant raises the question if and how the cells will maintain the osmotic pressure of the cytoplasm. It is conceivable that inorganic ions such as $\mathrm{K}^{+}$and $\mathrm{Cl}^{-}$may temporarily serve to maintain osmotic pressure [67], and that the pool of organic osmolytes will be replenished in the subsequent light period.

A few cyanobacteria are capable of accumulating poly- $\beta$-hydroxybutyrate (PHB) [68] but there is no evidence that this storage compound is used in dark energy metabolism. Decomposition would require the tricarboxylic acid (TCA) cycle which is absent in all of the cyanobacteria investigated. Stal [68] proposed a role as $\mathrm{C}$ reserve for $\mathrm{PHB}$, providing intermediates for biosynthesis. A role of PHB in cyanobacteria similar to that found in the purple sulfur bacterium Chromatium vinosum [42] was also considered. However, in $O$. limosa PHB was not formed as a product of fermentation even when sulfur as electron acceptor was present (L.J. Stal, unpublished results).

Some cyanobacteria contain cyanophycin (multi-Larginine poly-L-aspartic acid) which serves as a nitro- gen reserve [69]. It has been proposed that cyanobacteria may degrade arginine to ornithine via the dihydrolase route, which would allow the production of ATP by substrate-level phosphorylation, even under anaerobic conditions in the dark [1]. However, this has not been demonstrated and Stal et al. [70] concluded that this mode of energy generation did not occur in $O$. limosa.

\subsection{Fermentation products and the diversity of fermentation pathways}

The first cyanobacterium reported to be capable of fermentative energy generation was $O$. limnetica [44]. This organism carries out a homolactic fermentation, and produces about $1.4-1.8 \mathrm{~mol}$ of lactate per mol of glucose degraded. Although the pathway involved was not examined it is likely that conversion of glucose to lactate, as in lactic acid bacteria, involves the Embden-Meyerhof-Parnas glycolytic pathway. In contrast, the marine benthic cyanobacterium $O$. limosa degrades glycogen via the heterolactic fermentation pathway, which shares some sequences with 
glycogen $\longrightarrow \longrightarrow$ glucose-6-P

11
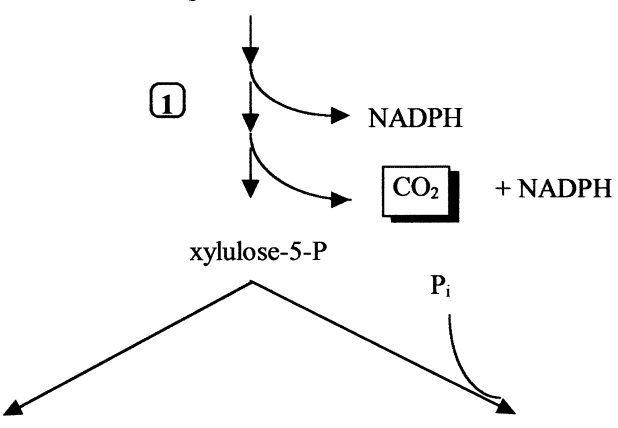

glyceraldehyde-3-P

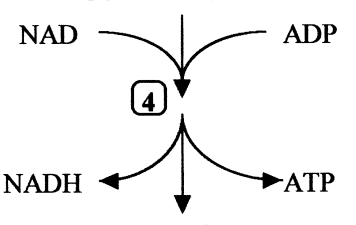

acetyl phosphate

phosphoenolpyruvate
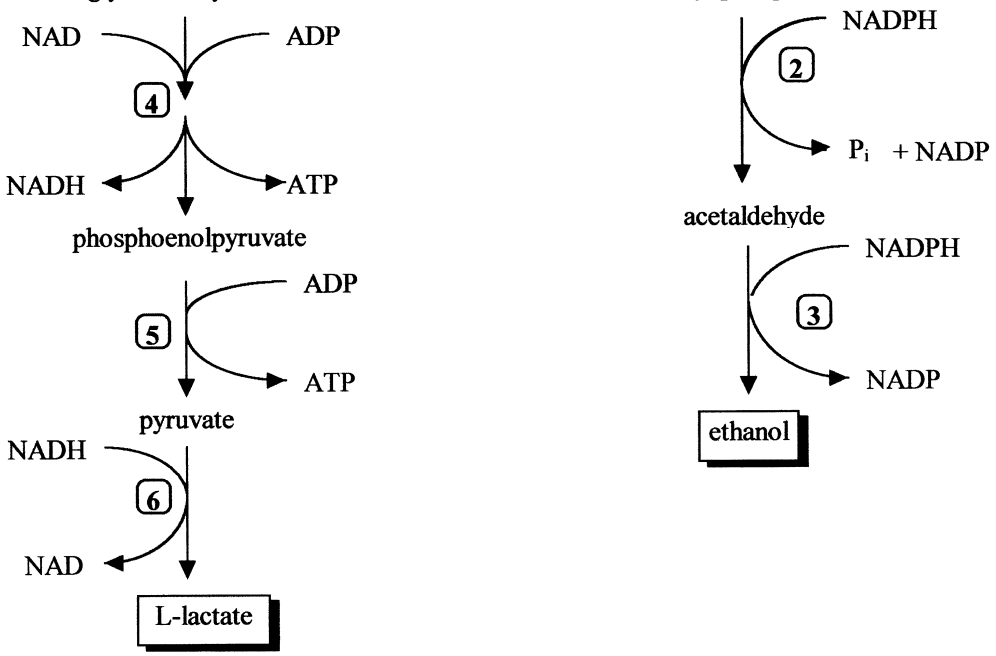

acetaldehyde

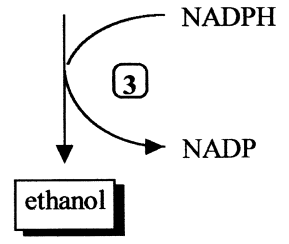

Stoichiometry: 1 glycogen-glucose

$\rightarrow 1$ lactate +1 ethanol +2 ATP

Fig. 1. Pathway of heterolactic acid fermentation in Oscillatoria limosa. The products of fermentation are shown in boxes. The numbers refer to the enzymes involved: 1 , enzymes of the oxidative pentose phosphate pathway; 2 , acetaldehyde dehydrogenase; 3 , alcohol dehydrogenase; 4, enzymes of the Embden-Meyerhof-Parnas pathway; 5, pyruvate kinase; 6, L-lactate dehydrogenase.

the oxidative pentose phosphate pathway (Fig. 1) [63]. The freshwater unicellular species Cyanothece PCC7822 performs a mixed acid fermentation with formate as characteristic fermentation product [60]. Based on the ratios of glucose utilization and product formation it was calculated that both the glycolytic and the oxidative pentose phosphate pathway were operative during fermentation (Figs. 1, 3 and 4). However, the enzymes that were demonstrated in cell-free extracts did not include the key enzymes of the glycolytic pathway (6-phosphofructokinase) and the phosphoketolase pathway (phosphoketolase) [71]. Whereas homoacetic fermentation is already quite rare among chemoheterotrophic bacteria, it has been reported to occur in several cyanobacterial species. The production of three mol of acetate from one mol of glucose by the symbiotic, diazotrophic cyanobacterium Nostoc sp. strain Cc and the absence of other products strongly suggested a homoacetic fermentation, but no enzymatic evidence was given for this [62]. Also in O. limosa this type of fermentation was reported to occur but curiously not with glycogen as the substrate [63]. These authors noticed that the production of acetate did not correlate with glycogen degradation. Moreover, the degradation of glycogen was fully accounted for by the fermentation 


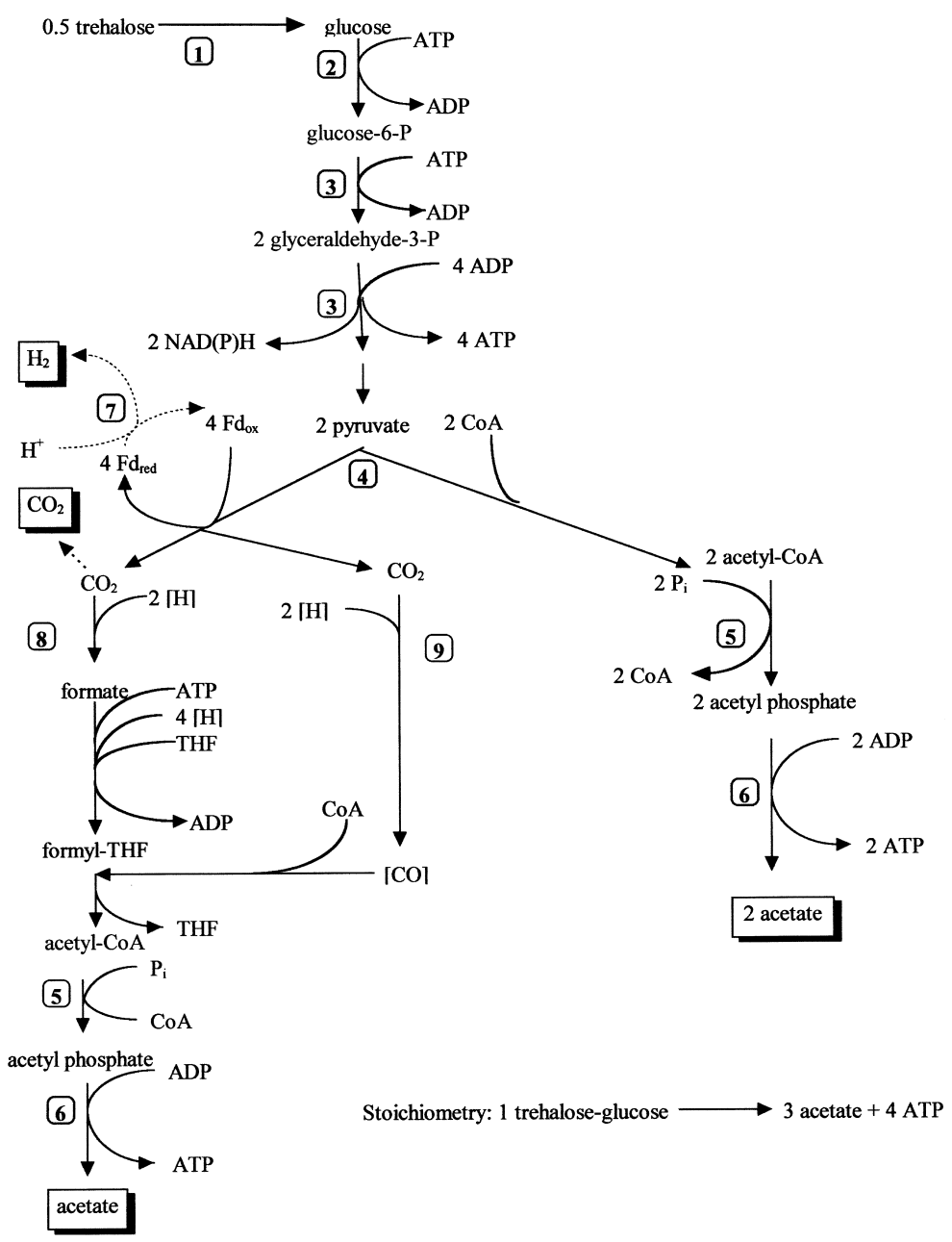

Fig. 2. Pathway of homoacetate fermentation in Oscillatoria limosa. The products in boxes are the fermentation products that are produced. The broken lines indicate reactions of relatively minor importance. The fermentation of trehalose yields 5 acetate instead of 6 . The balance is made by $\mathrm{H}_{2}$ and $\mathrm{CO}_{2}$. Although the ATP balance of acetate formation from $\mathrm{CO}_{2}$ is zero, the energy liberated by this pathway must be conserved by other mechanisms. It is likely that this is achieved electrochemically, e.g. by the generation of a $\mathrm{Na}^{+}$gradient [72]. The numbers refer to the enzymes involved: 1, trehalase; 2, hexokinase; 3, enzymes of the Embden-Meyerhof-Parnas pathway; 4, pyruvate:ferredoxin oxidoreductase; 5 , phosphotransacetylase; 6 , acetate kinase; 7 , hydrogenase; 8 , formate dehydrogenase; 9 , carbon monoxide dehydrogenase. THF, tetrahydrofolic acid.

products lactate and ethanol. Instead the production of acetate was found to correlate with the degradation of trehalose, which serves as osmoprotectant in $O$. limosa. For each mol of trehalose degraded 5-6 mol of acetate was recovered (Fig. 2). The use of osmoprotectant as substrate for fermentative energy generation is surprising and it is unknown why this compound is used for this purpose and how osmotic equilibrium of the cell cytoplasm is maintained. The occurrence of the homoacetic fermentation pathway in $O$. limosa was supported by the demonstration of the key enzymes in cell-free extracts $[63,73]$ (i.e. formate dehydrogenase, carbon monoxide dehydrogenase, pyruvate:ferredoxin oxidoreductase and acetate kinase). Also the presence and activity of trehalase was demonstrated in cell-free extracts of $O$. limosa. The source of the nitrogenase-independent production of $\mathrm{H}_{2}$ by this organism is a reversible hydro- 


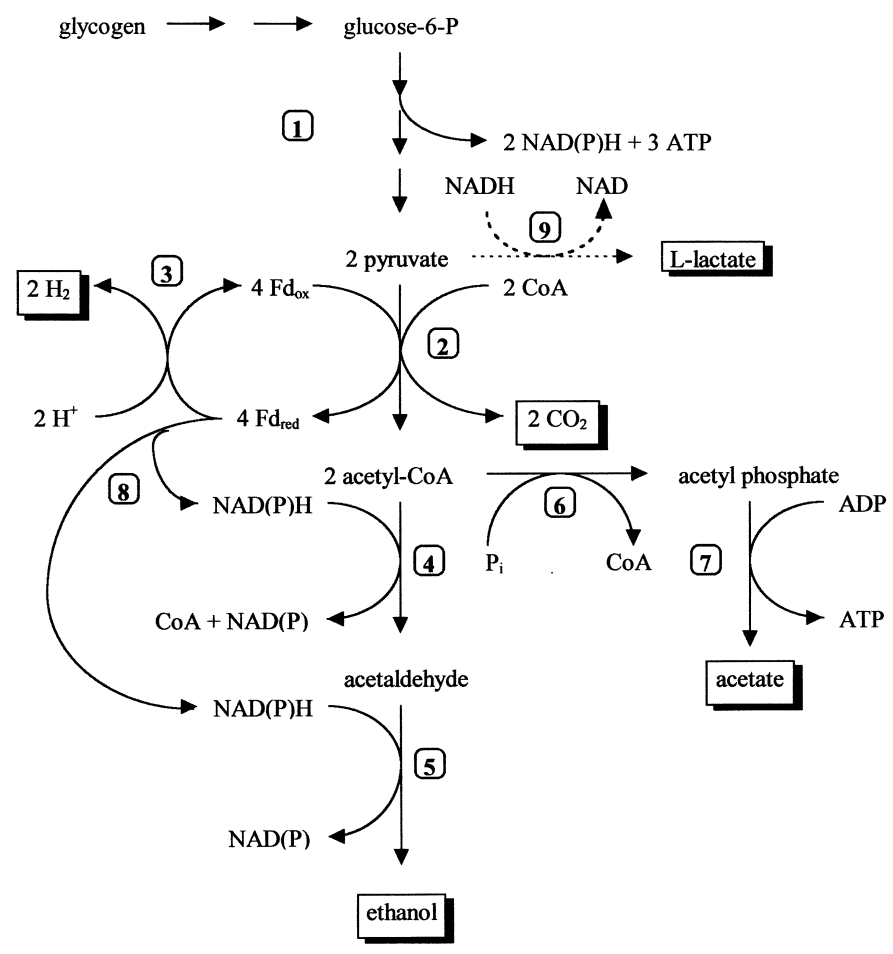

Stoichiometry: 1 glycogen-glucose

1 acetate +1 ethanol $+2 \mathrm{H}_{2}+2 \mathrm{CO}_{2}+4$ ATP

Fig. 3. Pathway of glycogen fermentation in the unicellular cyanobacterium Microcystis PCC7806. Compounds in boxes are possible fermentation products. Broken line: reaction only occurs in case of overflow metabolism but is not a regular fermentation product. The numbers refer to the enzymes involved: 1, enzymes of the Embden-Meyerhof-Parnas pathway; 2, CoA-linked pyruvate:ferredoxin oxidoreductase; 3, hydrogenase; 4, CoA-linked aldehyde dehydrogenase; 5, alcohol dehydrogenase; 6, phosphotransacetylase; 7, acetate kinase; 8, ferredoxin:NADP oxidoreductase; 9, NAD-dependent lactate dehydrogenase. This pathway has also been proposed to occur in the unicellular cyanobacterium Cyanothece PCC7822.

genase $[70,74]$. Homoacetic fermentation in $O$. limosa usually yielded a little less than the 6 acetate that should be expected from the degradation of trehalose, and the balance was made up by some $\mathrm{CO}_{2}$ and $\mathrm{H}_{2}$. It was proposed that the source of hydrogen was the reduced ferredoxin produced from the decarboxylation of pyruvate by pyruvate:ferredoxin oxidoreductase (Fig. 2).

More recently, Moezelaar and Stal [22] reported a mixed acid fermentation in the unicellular cyanobacterium Microcystis aeruginosa PCC 7806, a freshwater species known to produce nuisance water blooms. This organism degraded glycogen via the Embden-Meyerhof-Parnas pathway, producing $\mathrm{CO}_{2}$, ethanol, acetate and some $\mathrm{H}_{2}$ (Fig. 3). In cells that were grown under a light-dark regime and that contained relatively low amounts of glycogen more than four times more ethanol was produced than acetate. This phenomenon was attributed to the activity of ferredoxin:NADP oxidoreductase. In contrast, cultures grown under continuous light and containing a large amount of glycogen formed about equimolar amounts of ethanol and acetate and, in addition, produced some lactate [37,75] (Fig. 3).

Moezelaar et al. [61] reported a mixed-acid fermentation in the marine benthic cyanobacterium $M$. chthonoplastes, a cosmopolitan microbial matforming organism. As was the case in O. limosa, $M$. chthonoplastes not only fermented glycogen but also part of its osmoprotectant. The heteroside $O-\alpha-$ 


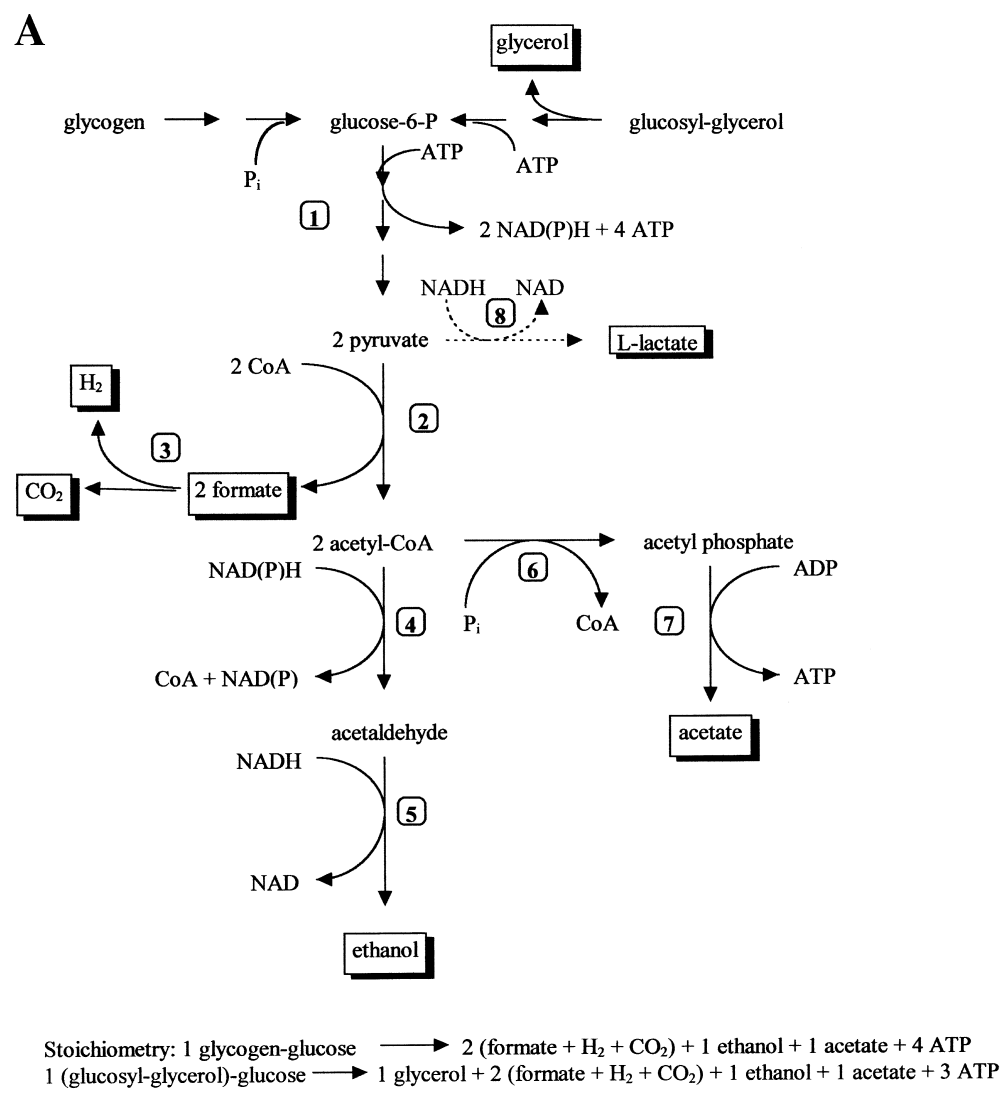

Fig. 4. Pathways of anaerobic energy generation in the mat-forming cyanobacterium Microcoleus chthonoplastes. A: Fermentation of glycogen and the osmoprotectant glucosyl-glycerol. B: Fermentation in the presence of elemental sulfur. C: Fermentation in the presence of ferric iron and/or elemental sulfur. The products in boxes are fermentation products excreted. The numbers refer to the enzymes involved: 1, enzymes of the Embden-Meyerhof-Parnas pathway; 2, pyruvate formate-lyase; 3, formate hydrogen-lyase; 4, CoA-linked aldehyde dehydrogenase; 5, alcohol dehydrogenase; 6 , phosphotransacetylase; 7, acetate kinase; 8 , NAD-dependent lactate dehydrogenase. The enzymes pyruvate formate-lyase and formate hydrogen-lyase have been suggested to play a role in fermentation in the unicellular cyanobacterium Cyanothece PCC7822.

D-glucopyranosyl-(1,2)-glycerol (glucosyl-glycerol) serves as osmoprotectant in $M$. chthonoplastes. This was especially the case when the intracellular amount of glycogen was low. The organism produced equimolar amounts of ethanol, acetate and formate in addition to some $\mathrm{H}_{2}$. When $M$. chthonoplastes contained a large amount of glycogen, glucosyl-glycerol was not used. Such cultures produced some lactate in addition to the fermentation products mentioned above (Fig. 4A). Of glucosyl-glycerol only the glucose part was fermented while glycerol was excreted in the medium. When elemental sulfur was present sulfide was produced and acetate and $\mathrm{CO}_{2}$ were the main fermentation products. The production of $\mathrm{H}_{2}$ ceased and formate and ethanol were produced in small quantities (Fig. 4B). Formate could also be oxidized when ferric iron was present (Fig. 4C) [76].

\subsection{The enzymes involved in fermentation}

The pathways that cyanobacteria employ during fermentation have been deduced from the nature of fermentation products and the ratios in which they are formed, but in only four cyanobacteria, $O$. limosa [63], Cyanothece PCC7822 [60], M. aeruginosa [22] and $M$. chthonoplastes [61] has the assumption concerning the pathway been supported by the presence of the key enzymes in cell-free extracts (Table 3). 


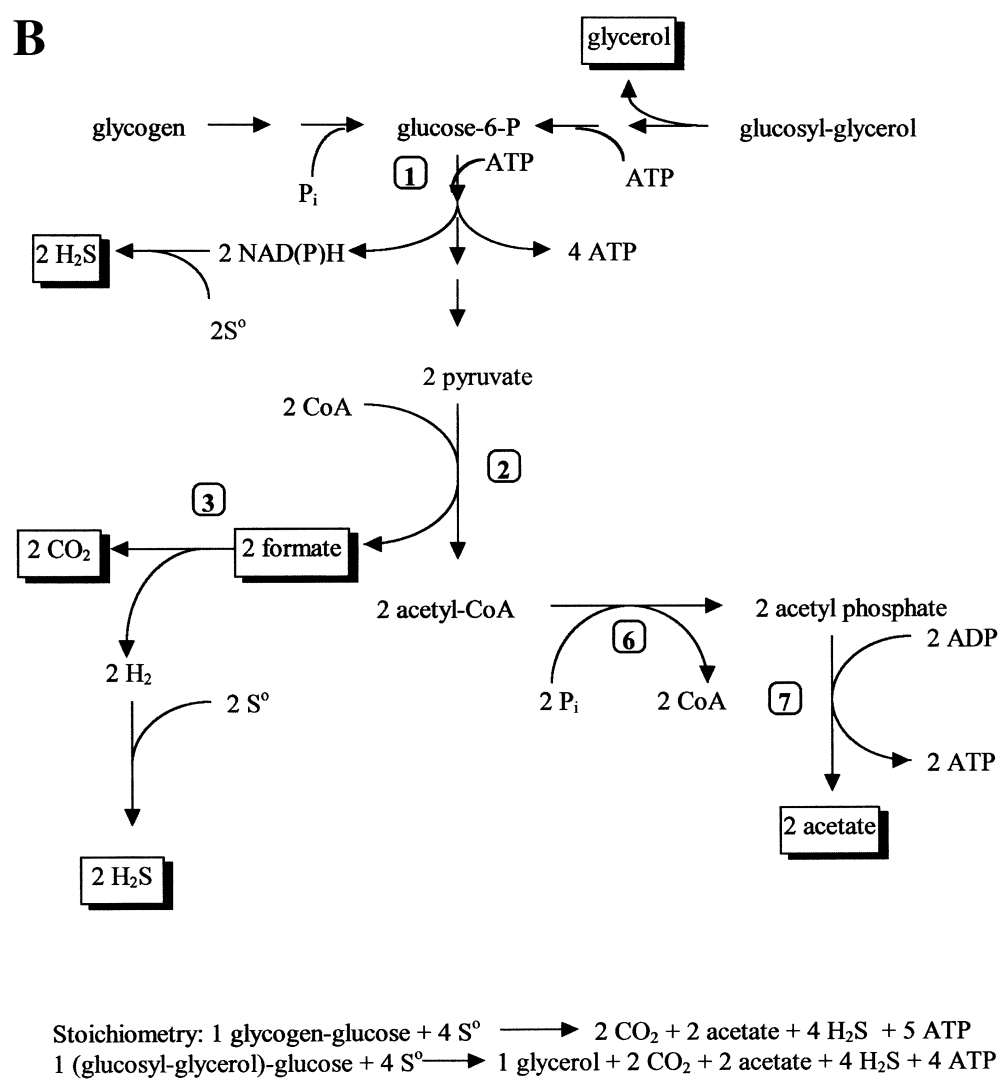

Fig. 4 (continued).

Likewise, the occurrence of certain enzymes might indicate the ability of fermentative energy generation. Such enzymes have indeed been reported to occur in cyanobacteria, but a role for these enzymes in fermentative metabolism was not considered. Instead, they were supposed to have other physiological functions.

The enzyme pyruvate:ferredoxin oxidoreductase is found in many obligately and facultatively anaerobic bacteria in which it is involved in fermentative degradation of pyruvate [77]:

$$
\begin{aligned}
& \text { pyruvate }+\mathrm{CoA}+2 \mathrm{Fd}_{\mathrm{ox}} \rightarrow \\
& \text { acetyl-CoA }+\mathrm{CO}_{2}+2 \mathrm{Fd}_{\text {red }}
\end{aligned}
$$

Among cyanobacteria, pyruvate:ferredoxin oxidoreductase was first found in two $\mathrm{N}_{2}$-fixing species
[78,79]. Since a catabolic role for the enzyme in a fermentative metabolism was not considered, the search for a function of pyruvate:ferredoxin oxidoreductase in cyanobacteria focused on a role in $\mathrm{N}_{2}$ fixation. Leach and Carr [78] suggested that in the heterocystous Anabaena variabilis the ferredoxin reduced by pyruvate:ferredoxin oxidoreductase could be used as electron donor for nitrogenase. This idea is supported by the observation of Neuer and Bothe [80] that in Anabaena cylindrica activity of pyruvate:ferredoxin oxidoreductase was almost exclusively confined to heterocysts. However, the nitrogenase-independent production of $\mathrm{H}_{2}$ under dark anoxic conditions by $A$. variabilis [81] and Anabaena PCC7120 [82] might involve pyruvate:ferredoxin oxidoreductase for the supply of reductant for hydrogenase. In O. limosa [63] and Cyanothece PCC7822 [60], pyruvate:ferredoxin oxidoreductase indeed ap- 


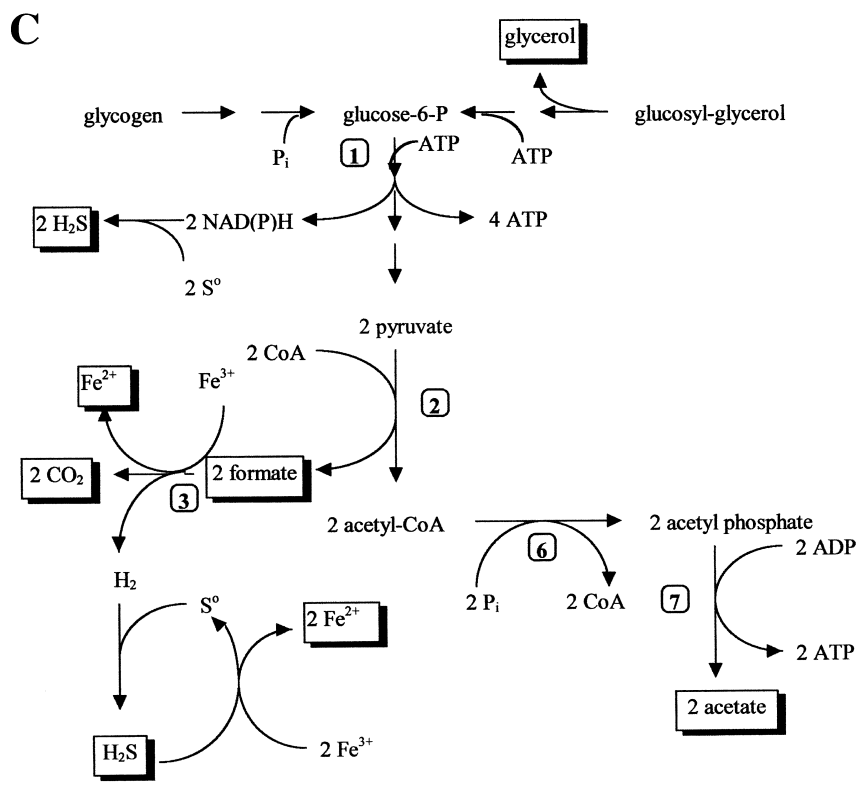

Stoichiometry: 1 glycogen-glucose $+\mathrm{x} \mathrm{S}^{\mathrm{o}}+8 \mathrm{Fe}^{3+} \longrightarrow 2 \mathrm{CO}_{2}+2$ acetate $+\mathrm{x} \mathrm{S}^{\mathrm{o}}+8 \mathrm{Fe}^{2+}+5$ ATP
1 (glucosyl-glycerol)-glucose $+\mathrm{x} \mathrm{S}^{0}+8 \mathrm{Fe}^{3+} \longrightarrow 1$ glycerol $+2 \mathrm{CO}_{2}+2$ acetate $+\mathrm{x} \mathrm{S}^{\circ}+8 \mathrm{Fe}^{2+}+4$ ATP

Fig. 4 (continued).

pears to serve both processes. When grown in a medium devoid of combined nitrogen, both organisms are capable of dark $\mathrm{N}_{2}$ fixation, whereas in nitrategrown cells the enzyme is presumably involved in fermentative $\mathrm{H}_{2}$ production.

Sanchez et al. [83] reported the presence of NADdependent lactate dehydrogenases in a number of unicellular cyanobacteria. Under in vivo conditions these enzymes catalyze the conversion of pyruvate into lactate rather than the reverse reaction [84] (see also Section 4).

The enzymes acetate kinase and phosphotransacetylase in $A$. variabilis were assumed to be involved in the conversion of exogenous acetate to acetyl-CoA [85]. Acetyl-CoA synthetase, which is involved in many other bacteria in the activation of acetate, was not found in $A$. variabilis. In fermenting bacteria, acetate kinase and phosphotransacetylase operate in the opposite direction and thus provide a pathway for synthesis of ATP [77].

In Table 3 the specific activities of a number of enzymes with a possible function in fermentation in $O$. limosa, M. chthonoplastes, M. aeruginosa and Cyanothece sp. are given. In all cases the specific activities measured were sufficient to explain the in vivo observed rates of fermentation. The enzymes detected were used as confirmation for the supposed fermentation pathway as deduced from the nature and ratios of the fermentation products formed. When comparisons between the four cyanobacteria were possible it was noticeable that large differences in specific activities existed, except for acetate kinase which was in the same order of magnitude in all organisms.

\subsection{The Embden-Meyerhof-Parnas pathway}

All cyanobacteria examined thus far seem to employ the Embden-Meyerhof-Parnas (EMP) pathway during fermentation for degradation of glucose residues to pyruvate. Involvement of the EMP pathway has been assumed on the basis of similarity of the 
Table 3

Comparison of specific activities of enzymes involved in fermentation in the cyanobacteria Oscillatoria limosa (O. lim.), Microcoleus chthonoplastes (M. chthon.), Microcystis aeruginosa (M. aerug.) (PCC7806) and Cyanothece sp. (PCC7822).

\begin{tabular}{|c|c|c|c|c|}
\hline $\begin{array}{l}\text { Enzyme } \\
\text { Fermentation }\end{array}$ & $\begin{array}{l}\text { O. } \mathrm{lim} \text {. } \\
\text { Heterolactic (glycogen) } \\
\text { Homolactic (trehalose) }\end{array}$ & M. chthon. & $\begin{array}{l}\text { M. aerug. } \\
\text { Mixed acid }\end{array}$ & Cyanothece \\
\hline Acetate kinase & 24 & 76 & 51 & 30.2 \\
\hline Lactate dehydrogenase & $4^{\mathrm{a}}$ & 41 & 160 & $4.2^{\mathrm{a}}$ \\
\hline Alcohol dehydrogenase (NADH) & $4^{\mathrm{b}} 0$ & 0 & 0 & nd \\
\hline Formate dehydrogenase & 4 & 0 & nd & nd \\
\hline Pyruvate:Ferredoxin oxidoreductase & 5.4 & nd & 30 & 4.2 \\
\hline Formate: $\mathrm{H}_{2}$ lyase & nd & nd & nd & 0.3 \\
\hline Pyruvate:Formate lyase & nd & nd & nd & 1.8 \\
\hline Pyruvate kinase & nd & 37 & 63 & nd \\
\hline 6-Phosphogluconate dehydrogenase & nd & 85 & $40^{c}$ & nd \\
\hline
\end{tabular}

Specific activities in $\mathrm{nmol}(\mathrm{mg} \text { protein })^{-1} \mathrm{~min}^{-1}$; nd: not determined.

${ }^{a}$ Not analyzed under optimal conditions: in the presence of $5 \mathrm{mM}$ pyruvate and $10 \mathrm{mM}$ fructose-1,6-bisphosphate [75] and therefore these activities may be much higher.

${ }^{b}$ Measured colorimetrically and not known whether the activity is NADH- or NADPH-dependent. Data of $O$. limosa from [63,70,73,74], of M. chthonoplastes from [61], of M. aeruginosa from [22] and of Cyanothece PCC7822 from [71].

${ }^{\mathrm{c}}$ These activities were measured in cultures grown under an alternating light-dark cycle $(16-8 \mathrm{~h})$, whereas all other activites were measured in cultures grown under continuous light.

fermentation pattern to those of other bacteria $[22,44,60,61,63]$, but for only three species, $O$. limosa [73], Microcystis PCC7806 [22] and M. chthonoplastes [61], has this assumption been confirmed by the presence of the key enzyme of the EMP pathway, 6-phosphofructokinase, in cell-free extracts of axenic cultures (Table 3). In $O$. limosa the activity of 6phosphofructokinase was very low but in the other two organisms the specific activity of this enzyme was sufficiently high to account for the rate of glucose degradation by cell suspensions. As far as we are aware these reports were the first that associated the presence of 6-phosphofructokinase in cyanobacteria with a physiological function.

The occurrence of 6-phosphofructokinase and the physiological significance of the EMP pathway in cyanobacteria as a route for glucose degradation has been a matter of uncertainty for a long time. While significant specific activities of 6-phosphofructokinase were found in several species, the activity detected in others was so low that a metabolic func- tion was not even conceived (Table 4). However, there is evidence that failure to detect significant activities of this enzyme may be due to absence of stabilizing compounds during preparation of the

Table 4

6-Phosphofructokinase in cell-free extracts of cyanobacteria

\begin{tabular}{lll}
\hline Organism & Spec. activity & Ref. \\
\hline Aphanocapsa PCC6308 & $<0.1$ & {$[86]$} \\
Aphanocapsa PCC6714 & $<0.1$ & {$[86]$} \\
Anabaena cylindrica & 1.8 & {$[80]$} \\
Anabaena variabilis & 17 & {$[87]$} \\
& 8.1 & {$[88]$} \\
Anacystis nidulans & 13 & {$[87]$} \\
& 5.8 & {$[89]$} \\
Nostoc muscorum & 25 & {$[87]$} \\
Microcystis PCC7806 & 18 & {$[22]$} \\
Microcoleus chthonoplastes & 8 & {$[61]$} \\
Oscillatoria limosa & 0.005 & {$[63]$} \\
Synechococcus PCC6301 & $<0.1$ & {$[86]$} \\
Synechococcus PCC6716 & 1.3 & {$[83]$} \\
\hline
\end{tabular}

The specific activities are given in $\mathrm{nmol} \mathrm{min}^{-1}(\mathrm{mg} \text { protein })^{-1}$. 
cell-free extract. In cell-free extracts of $M$. chthonoplastes, no 6-phosphofructokinase is detected unless its substrate, fructose-6-phosphate, is added to the cell suspension prior to cell breakage [61]. Omission leads to a complete loss of activity which cannot be restored by adding it to the assay mixture. Similarly, Fewson et al. [87] reported that in Anabaena variabilis, Anacystis nidulans, and Nostoc muscorum no activity of 6-phosphofructokinase was detected unless extracts were prepared with cysteine present. This may also have been the reason for the very low activity observed in $O$. limosa [73] (Table 3). Thus, this enzyme may be more widely distributed among cyanobacteria than has been assumed so far.

The presence of significant specific activities of 6phosphofructokinase in several strains raised the question of what purpose this enzyme served in cyanobacteria. A role in photoautotrophic metabolism is difficult to imagine. During photoautotrophic growth, $\mathrm{CO}_{2}$ fixed in the Calvin cycle enters the metabolism as 3-phosphoglycerate. Conversion of 3phosphoglycerate to fructose-6-phosphate, which is part of the Calvin cycle, involves some of the sequences of the EMP pathway in the reverse direction. This series of reactions, however, does not include 6-phosphofructokinase, since the reaction catalyzed by this enzyme, the phosphorylation of fructose-6phosphate to fructose-1,6-bisphosphate, is virtually irreversible and thus serves the EMP pathway only in the direction of pyruvate formation. A role for 6phosphofructokinase in dark aerobic energy generation is not very likely either. Degradation of glucose residues via glycolysis would only be conceivable in combination with the TCA cycle. However, cyanobacteria lack the enzyme $\alpha$-ketoglutarate dehydrogenase and thus do not possess a complete TCA cycle. Moreover, changes in the size of metabolite pools upon transfer from light to dark and the presence of the enzymes glucose-6-phosphate dehydrogenase and 6-phosphogluconate dehydrogenase have identified the oxidative pentose phosphate (OPP) pathway as the most likely route of aerobic glycogen degradation (reviewed by Smith [1]). It is therefore conceivable that in cyanobacteria 6-phosphofructokinase serves primarily, if not exclusively, the fermentative metabolism, and that its presence in a cyanobacterium indicates the capability of fermentation.
In O. limosa [63] and Cyanothece PCC7822 [60], the OPP pathway is also operative during fermentation. Remarkably, $O$. limosa employs the OPP pathway for degradation of glycogen, whereas the osmoprotectant trehalose is degraded via the glycolysis. Stal et al. [70] have proposed that the heterolactic acid and homoacetate fermentation in this organism must be confined to different compartments in the cell. In their model the EMP pathway (involved in homoacetate fermentation) (Fig. 2) is in the cytoplasm which contains the substrate trehalose, whereas the OPP pathway (partly involved in heterolactic acid fermentation) (Fig. 1) is in the thylakoid space where glycogen is stored (L.J. Stal, unpublished results). However, no conclusive evidence for this compartmentalization of these fermentation pathways in $O$. limosa is available.

\subsection{The capability of fermentation is constitutive}

All cyanobacteria examined thus far switch immediately from photoautotrophy to fermentation when exposed to dark anoxic conditions, suggesting that the ability for fermentation is constitutive, and that induction of new enzymes is not required. This has been confirmed for O. limnetica [44], Microcystis PCC7806 [22], and M. chthonoplastes [61], in which fermentation is not affected by the presence of antibiotics that inhibit protein synthesis. All enzymes are readily detected in photoautotrophically grown cells and anaerobic incubation did not induce higher enzyme activities in any of the cyanobacteria tested for this. Fermentation in these cyanobacteria is therefore not regulated at the level of expression of genes.

Onset of fermentation does not require strictly anoxic conditions, but occurs at reduced oxygen partial pressures [63]. In Nostoc sp. strain Cc fermentation occurs with $3.4 \%$ oxygen in the gas phase [62]. In $O$. limnetica fermentation occurs even under atmospheric oxygen levels when respiration is inhibited by the addition of cyanide [44]. Fermentation in cyanobacteria may be under control of a particular metabolite which may either inhibit or activate certain enzymes. Lactate dehydrogenase in $M$. aeruginosa is subject to such regulation [75] (see Section 4) but other examples are lacking. Nevertheless, a metabolic control of the pentose phosphate pathway must be conceived. In the light this pathway should operate in the re- 
ductive mode and allow oxidative processes only in the dark. Part of the OPP pathway is involved in heterolactic fermentation, which occurs in $O$. limosa [63]. In the majority of cyanobacteria fermentation involves the EMP pathway which does not seem to play a role in phototrophic metabolism. It is therefore also possible that fermentation pathways in these cyanobacteria lack a good regulation and give occasion to suppose that fermentation occurs regardless of the prevailing conditions. On the other hand, the activities of enzymes of fermentative pathways are so much lower than those involved in aerobic or phototrophic metabolism that fermentation pales into insignificance beside it. The advantage for the organism of possessing a constitutive anaerobic metabolism is its ability to quickly react to changes of environmental conditions.

\section{Lactate dehydrogenase and lactate production in cyanobacteria}

In a screening of 27 unicellular cyanobacteria (Synechococcus and Aphanocapsa spp.) for NAD-dependent lactate dehydrogenases, eight strains were found to possess both D- and L-lactate dehydrogenases whereas 12 strains were found to contain only D-lactate dehydrogenase [83]. Initially it was assumed that these were involved in the incorporation of exogenous lactate into biomass. However, it is now generally accepted that in vivo NAD-dependent lactate dehydrogenases function in the conversion of pyruvate to lactate rather than in the opposite direction [84]. Excretion of D-lactate under dark anoxic conditions as an end product of endogenous carbohydrate catabolism has been reported for Synechococcus PCC6716 [83]. No attempts were made to determine other fermentation products but, according to the authors, the amount of lactate produced "corresponded fairly well" with the decrease in carbohydrate during such incubations. Conversion of glycogen to lactate in this organism may involve the EMP pathway, since most of the enzymes of this route, including the key enzyme 6-phosphofructokinase and NAD-linked D-lactate dehydrogenase, were demonstrated in cell-free extracts [83]. Synechococcus PCC6716 is not capable of fermenting exogenous glucose.
Moezelaar et al. [75] found NAD-dependent lactate dehydrogenase (LDH) (EC 1.1.1.27) in the unicellular cyanobacterium Microcystis aeruginosa PCC 7806, although they were initially unable to detect any lactate production during fermentation. This was remarkable since the specific activity of $\mathrm{LDH}$ in Microcystis PCC7806 was 0.14-0.16 U (mg protein $)^{-1}$ the highest reported of cyanobacterial cell-free extracts. Activity of LDH from Microcystis PCC7806 was like other NAD-dependent LDHs inhibited by ATP and ADP [83,84]. However, the enzyme of Microcystis was not inhibited by inorganic phosphate which is known as a general inhibitor of fructose-1,6-bisphosphate-dependent lactate dehydrogenases [84]. The significance of these regulations of $\mathrm{LDH}$ in Microcystis are not clear. Recently, using cultures with high levels of glycogen Moezelaar and Stal could show also small amounts of L-lactate among the fermentation products [37]. Lactate dehydrogenase activity appeared to be tightly regulated in $M$. aeruginosa. The enzyme required the EMP pathway intermediate fructose-1,6-bisphosphate for activity and displayed positive cooperativity towards pyruvate [75]. Moezelaar and Stal [37] concluded that the role of NAD-dependent lactate dehydrogenase in this organism is probably overflow metabolism as it is in certain other bacteria [84]. However, in these organisms this type overflow metabolism depends on the amount of extracellular substrate offered. In this respect the observation of De Philippis et al. [10] is of interest. These authors studied a large number of different strains of symbiotic and free-living heterocystous cyanobacteria of the genera Nostoc and Anabaena. These strains were all able to utilize exogenous sugars and ferment them under anoxic conditions in the dark probably via the homoacetic acid pathway. Most of these strains produced variable amounts of lactate. These results also hint to a role in overflow metabolism.

In other strains lactate is among the normal fermentation products. In $O$. limnetica glucose is fermented via the homolactic acid pathway and lactate is the only product [44]. These authors did not measure LDH activity and therefore the characteristics of this enzyme are not known. The analytical procedure also did not allow conclusions about whether L- or D-lactate was produced. $O$. limosa ferments glycogen via the heterofermentative lactic acid pathway, pro- 
ducing L-lactate as fermentation product in addition to ethanol [63]. NAD-dependent LDH was determined and amounted to $0.004 \mathrm{U}$ (mg cell protein) ${ }^{-1}$. One unit (U) of enzyme activity is defined as the amount of enzyme catalyzing the transformation of $1 \mu \mathrm{mol}$ of substrate or the formation of $1 \mu \mathrm{mol}$ of product in $1 \mathrm{~min}$. Also in Microcoleus chthonoplastes NAD-dependent LDH was present $(0.041 \mathrm{U}$ (mg protein $)^{-1}$ ) but small amounts of lactate were produced only in cultures that contained a large amount of glycogen [61] and it is probable therefore that this enzyme is regulated in the same manner as in Microcystis. Van der Oost et al. [60] found lactate as a normal fermentation product in the unicellular cyanobacterium Cyanothece PCC7822. Van der Oost [71] also measured NAD-dependent LDH but his analyses did not allow the distinction between Dor L-lactate as the fermentation product. O. terebriformis produced small amounts of lactate when incubated anaerobically in the dark with a large amount (30 $\mathrm{mM})$ of fructose (or glucose) as substrate [28].

In summary it can be concluded that lactate production in cyanobacteria is either a main fermentation product or is only produced as a product of overflow metabolism when alternative fermentation pathways are saturated. Cyanobacteria that produce lactate as main fermentation product may either lack a tight regulation of $\mathrm{LDH}$ or produce lactate because of the absence of other fermentation pathways.

\section{Hydrogenases}

The capability of cyanobacteria to evolve molecular hydrogen has been known for a long time. Of the three enzymes involved in $\mathrm{H}_{2}$ metabolism in cyanobacteria (reviewed by Houchins [90]), two are known to catalyze the evolution of $\mathrm{H}_{2}$ in vivo: nitrogenase, which obligately produces $\mathrm{H}_{2}$ as a by-product of $\mathrm{N}_{2}$ fixation, and reversible or soluble hydrogenase. Nitrogenase-linked production of $\mathrm{H}_{2}$ is not considered here since it is an inherent property of the enzyme and hence does not seem to serve a particular function in fermentation. In contrast, the reversible hydrogenase resembles the enzyme that in many chemoorganotrophic bacteria is involved in fermentative production of $\mathrm{H}_{2}$ as a means of releasing ex- cess reductant [77]. Hydrogenase-dependent $\mathrm{H}_{2}$ evolution under dark anoxic conditions at the expense of endogenous substrate has been observed with cyanobacteria of various genera [81,91-96]. In Anabaena cylindrica, hydrogenase is activated after $1-5 \mathrm{~h}$ of dark anaerobic incubation [81]. Additional synthesis of hydrogenase has been observed during anaerobic incubation in the light $[82,96]$ or upon depletion of $\mathrm{NH}_{4}^{+}$[95].

\section{Electron acceptors and anaerobic respiration}

In addition to lactate fermentation, $O$. limnetica exhibits a second mode of anaerobic glucose catabolism in the dark [44]. In the presence of elemental sulfur a considerable part of the endogenous carbohydrates is oxidized completely to $\mathrm{CO}_{2}$ and concomitantly elemental sulfur is reduced to sulfide. The remaining part of the glucose is fermented to lactate. Other sulfur compounds like thiosulfate or sulfate were not used as electron acceptors. It was assumed that the use of elemental sulfur as electron acceptor represented a true sulfur respiration but this was not convincingly demonstrated. As we argue in Section 7, sulfur respiration would yield only an insignificantly larger amount of ATP in this organism.

$O$. limosa is also capable of reducing elemental sulfur to sulfide under dark anoxic conditions [63]. For this organism elemental sulfur acts as a sink for electrons that are otherwise released as $\mathrm{H}_{2}$ and does not affect the formation of the other fermentation products. Synechococcus lividus strain Y52, isolated from a hot spring microbial mat, reduces thiosulfate and sulfate to sulfide when incubated anaerobically in the dark $[97,98]$. The physiological status of this process is not clear since production of sulfide from (thio)sulfate occurs at even higher rates in the light when $\mathrm{CO}_{2}$ is absent.

The mat-forming cyanobacterium $M$. chthonoplastes reduced elemental sulfur during anaerobic dark metabolism $[59,61]$. As can be seen from Table 5 the addition of elemental sulfur had the following effects. The amount of acetate produced almost doubled while the production of ethanol decreased to the same extent. This is an important aspect since one additional ATP is generated for each acetate produced (Fig. 4B). Other effects were the much low- 
Table 5

Comparison of fermentation in Microcoleus chthonoplastes in the presence and absence of elemental sulfur

\begin{tabular}{lll}
\hline Product & $-\mathrm{S}^{\circ}$ & $+\mathrm{S}^{\circ}$ \\
\hline Ethanol & 1.04 & 0.31 \\
Acetate & 1.00 & 1.72 \\
Formate & 0.72 & 0.28 \\
$\mathrm{H}_{2}$ & 0.09 & 0 \\
$\mathrm{CO}_{2}$ & 1.32 & 1.75 \\
Sulfide & 0 & 2.28 \\
\hline
\end{tabular}

Amounts are expressed as mol per mol of glucose fermented. Data from [61].

er production of formate and the complete cessation of hydrogen evolution, while sulfide was formed. By comparing the fermentation of $M$. chthonoplastes with and without elemental sulfur (Table 5) it can be concluded that elemental sulfur serves as an electron sink in this organism. In the absence of elemental sulfur the cleavage of formate seems to be limited by the accumulation of $\mathrm{H}_{2}$, which makes this reaction thermodynamically less favorable [77]. When sulfur is present much more formate is cleaved, because instead of $\mathrm{H}_{2}$ the thermodynamically more favorable sulfide is produced. Unless sulfur serves as terminal electron acceptor in a respiratory electron transport system, the only advantage of this reaction may be the removal of the toxic formate. In its natural environment, microbial mats, the sulfide produced will normally precipitate as $\mathrm{FeS}$ which will eliminate toxic effects of sulfide. On the other hand other microorganisms in the ecosystem may use $\mathrm{H}_{2}$ or formate (e.g. sulfate-reducing bacteria) and therefore it is uncertain whether this sulfide production will take place under natural conditions. More importantly, sulfur reduction could also regenerate NAD(P) reduced during glucose oxidation in the EMP pathway. In the absence of elemental sulfur the reduction of acetyl-CoA to ethanol serves the regeneration of $\mathrm{NAD}(\mathrm{P})$. The obvious advantage of the presence of sulfur is that more acetyl-CoA can be converted into acetate, allowing the production of ATP. Theoretically, when sulfur serves as terminal electron acceptor in a respiratory electron transport chain, its reduction could also yield energy. A higher energy yield should be translated in a larger amount of biosynthesis. This was not the case. The $q_{\mathrm{ATP}}$ of the culture incubated without elemental sulfur in- creases from 1.34 to $1.46\left(\mathrm{nmol} \mathrm{min}{ }^{-1}\right.$ (mg cell protein $)^{-1}$ ) when compared with a culture in the presence of sulfur. The carbon and redox balances of the latter fermentation indicate that despite the higher energy yield less biosynthesis could have taken place. Because of this, the energy available for maintenance purposes increased from $q_{\mathrm{ATP}}^{\mathrm{m}} 0.88$ to

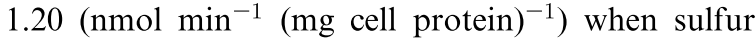
was present. Thus, if the reduction of sulfur itself were associated with energy generation, it could be questioned for what purpose, since it did not increase biosynthesis.

An interesting difference between sulfur reduction in $M$. chthonoplastes and $O$. limnetica is that in the latter electrons apparently are generated via the OPP pathway, which is clearly not the case in Microcoleus. Because cyanobacteria lack the TCA cycle [1] and $O$. limnetica oxidizes glycogen almost completely to $\mathrm{CO}_{2}$ in the presence of sulfide, it is inevitable that degradation is via the OPP pathway, which is also the route when glycogen is metabolized aerobically [1]. Apparently the OPP pathway is blocked in $M$. chthonoplastes under anoxic conditions, even when sulfur is present as electron acceptor. If, as we believe, sulfur does not serve as a terminal acceptor in a respiratory electron transport chain in this organism, oxidation of glucose via the OPP pathway would not yield any energy at all. In $O$. limnetica, on the other hand, sulfur could play a role as terminal electron acceptor in anaerobic respiration but as Oren and Shilo [44] calculated the energy yield of this process would be only slightly higher than in the case of fermentation.

The reduction of sulfur is widely distributed in the microbial world but in only few cases it is associated with an electron transport chain [99]. Virtually all cyanobacteria we have tested, appeared to be capable of reducing elemental sulfur (Table 6). However, further investigations are required in order to prove whether cyanobacteria are capable of true sulfur respiration.

Oren and Shilo [44] have tested the possibility of sulfate and thiosulfate serving as electron acceptors in anaerobic dark metabolism in $O$. limnetica with a negative result. We have done the same for $M$. chthonoplastes and also concluded that sulfate, sulfite and thiosulfate could not serve as electron acceptors in anaerobic dark metabolism in this organism (L.J. 
Stal, unpublished results). The utilization of sulfate and thiosulfate as electron acceptors in dark anaerobic metabolism has been reported for the unicellular cyanobacterium $S$. lividus Y52-s [97,98]. This organism reduces sulfate to sulfide and thiosulfate to sulfite and sulfide while endogenous carbohydrate is oxidized to $\mathrm{CO}_{2}$. Exogenous carbohydrates were not utilized. In the absence of $\mathrm{CO}_{2}$, sulfate and thiosulfate were also reduced in the light. As far as we are aware, $S$. lividus is the only organism known with this type of anaerobic metabolism, which could present a mode of anaerobic respiration, or a deregulated assimilatory sulfate reduction [101].

Moezelaar et al. [61] considered the possibility that ferric iron could serve as an electron acceptor in anaerobic dark metabolism in $M$. chthonoplastes. It was already known that this organism is capable of accumulating and reducing ferric iron [102]. Schaub and Stal [76] demonstrated that $M$. chthonoplastes is capable of reducing ferric iron mediated through the oxidation of the fermentation product formate, but they also showed that the rate at which this occurred was much too slow to be significant as electron acceptor during fermentation. These authors suggested that formate mediated iron reduction rather plays a role in iron acquisition. However, iron may indirectly serve as electron acceptor when sulfur is present [102]. The sulfide formed from the reduction of elemental sulfur will reduce ferric iron according to the following reaction:

$2^{3+}+\mathrm{S}^{2-} \rightarrow 2 \mathrm{Fe}^{2+}+\mathrm{S}^{\circ}$

Van Bergeijk and Stal [103] investigated the possibility of dimethylsulfoxide (DMSO) serving as electron acceptor in anaerobic dark metabolism in $M$. chthonoplastes. They indeed showed that this organism reduced DMSO to dimethylsulfide (DMS) but were unable to associate this process with fermentative metabolism. Unlike elemental sulfur the presence of DMSO did not alter the fermentation pattern. Moreover, as was the case with ferric iron, the rate of reduction was much too slow to be important as electron acceptor during fermentation. DMSO as well as trimethylamine- $N$-oxide (TMAO) have been shown to serve as electron acceptors in anaerobic dark metabolism in anoxygenic phototrophic bacteria $[40,41]$.

In the filamentous non-heterocystous nitrogen-fixing cyanobacterium $O$. limosa acetylene could serve as an electron acceptor [59]. Under a helium atmosphere, nitrogen-fixing $O$. limosa produced hardly detectable amounts of lactate and no sulfide when acetylene $\left(\mathrm{C}_{2} \mathrm{H}_{2}\right)$ was present. Nitrogenase which normal function is the reduction of $\mathrm{N}_{2}$ in nitrogenfixing organisms is also capable of reducing acetylene to ethylene, a property widely used for the assay of nitrogenase activity [104]. In $O$. limosa nitrogenase activity under anaerobic conditions in the dark as measured by the acetylene reduction technique is $1.3 \mathrm{nmol} \mathrm{C}_{2} \mathrm{H}_{4} \mathrm{~min}^{-1}$ (mg protein) ${ }^{-1}$ [105]. Compared with the rate of glycogen utilization (1.1 nmol glucose $\min ^{-1}$ (mg cell protein $)^{-1}$, Table 7) and the rate of trehalose degradation $(0.2 \mathrm{nmol}$ trehalose $\min ^{-1}$ ( $\mathrm{mg}$ cell protein $)^{-1}$ [63]), it is obvious that a considerable amount of the electrons produced are transported via nitrogenase. Acetylene reduction followed precisely the kinetics of glycogen degradation [59]. In stead of yielding energy, nitrogenase mediated electron transport will be only at

Table 6

Cyanobacteria capable of sulfur reduction

\begin{tabular}{lll}
\hline Strain & Origin & Ref. \\
\hline Oscillatoria limosa & microbial mat, North Sea & {$[63]$} \\
Microcoleus chthonoplastes & microbial mat, North Sea & {$[61]$} \\
Merismopedia punctata & microbial mat, North Sea & {$[100]$} \\
Chroococcus turgidus & microbial mat, North Sea & {$[100]$} \\
Anabaena variabilis & microbial mat, North Sea & {$[100]$} \\
Spirulina subsalsa & microbial mat, North Sea & {$[100]$} \\
Oscillatoria limnetica & Solar Lake, Sinai & {$[44]$} \\
Aphanothece halophytica & saltern & {$[44]$} \\
Microcystis aeruginosa & freshwater lake, PCC7806 & Moezelaar and Stal, unpublished \\
\hline
\end{tabular}


Table 7

Glycogen degradation $\left(q_{\text {glucose }}\right)$ and ATP production (expected when glycogen is totally fermented) $\left(q_{\text {ATP }}\right)$ in cyanobacteria during fermentation

\begin{tabular}{lllll}
\hline Organism & $q_{\text {glucose }}$ & ATP/glucose & $q_{\text {ATP }}$ & Ref. \\
\hline $\begin{array}{l}\text { Oscillatoria limnetica } \\
\text { Oscillatoria limosa }\end{array} \quad 1.7$ & 3 & 5.1 & {$[44]$} & {$[63]$} \\
$\quad$ nitrate-grown & 0.8 & & 1.6 & 2.2 \\
$\quad \mathrm{~N}_{2}$-grown & 1.1 & 2 & 2.6 & {$[60]$} \\
Cyanothece PCC7822 & 0.8 & 2 & 8.5 & {$[62]$} \\
Nostoc sp. strain Cc. & 1.7 & 3.2 & $1.6-3.6$ & {$[22,37]$} \\
Microcystis PCC7806 & $0.4-0.9$ & 4 & $0.8-1.6$ & {$[61]$} \\
Microcoleus chthonoplastes & $0.2-0.4$ & 4 & 5 & \\
\hline
\end{tabular}

Rates are expressed in $\mathrm{nmol} \mathrm{min}^{-1}$ (mg cell protein $)^{-1}$. In order to convert published data from chlorophyll $a$ to protein the ratio $26: 1$ (protein:chlorophyll $a$ ) was used [61]. The rates refer only to glycogen degradation and not to extracellularly added glucose or degradation of osmoprotectant (see text). In case multiple pathways were assumed, the average ATP yield was calculated. The range of the rate of glycogen degradation is given when this varies with glycogen content.

the expense of a considerable amount of energy (2 ATP $\left(\mathrm{e}^{-}\right)^{-1}$ ) (see Section 7). The fermentation experiments with $O$. limosa were carried out under an atmosphere of either helium [59] or argon [63]. Unfortunately, no experiments were carried out under a nitrogen atmosphere, but the fact that acetylene reduction occurred anaerobically in the dark in nitrogen-fixing cultures makes it likely that molecular nitrogen $\left(\mathrm{N}_{2}\right)$ will serve as electron sink under such conditions.

\section{Energetics of fermentation in cyanobacteria}

\subsection{Maintenance requirements in cyanobacteria}

Compared to aerobic respiration the energy yield of fermentation is low. In the light, cyanobacteria accumulate energy storage material endogenously which is subsequently utilized in the dark. That this process does not serve solely maintenance purposes was demonstrated by Post et al. [7] who showed that the cyanobacterium $O$. agardhii when grown in continuous culture under a light-dark cycle was capable of maintaining its growth rate at the expense of endogenous carbohydrate during the dark period. These authors provided evidence that the energy yield of aerobic respiration was sufficient to sustain growth at the same rate as in the light. Apart from this work, remarkably little has been published about the energetics of dark metabolism in cyanobacteria. In general it is assumed that the energy yield of fermentation is so low that at best it can sustain maintenance [60]. However, very little is known about maintenance energy requirements in cyanobacteria [106].

In all cyanobacteria investigated thus far, degradation of glycogen during fermentation occurs at low rates ranging from 0.2 to $1.7 \mathrm{nmol} \mathrm{m^{-1 }}$ (mg cell protein $^{-1}$ (Table 7). Such rates are very low compared to uptake rates of glucose that are required to sustain growth during fermentation in other microorganisms. As shown for Enterococcus faecalis grown in glucose-limited chemostats, the glucose uptake rate increases with the specific growth rate from $80 \mathrm{nmol} \mathrm{min}-1$ (mg cell protein) $)^{-1}$ at $0.1 \mathrm{~h}^{-1}$ to 550 $\mathrm{nmol} \mathrm{min}^{-1}$ (mg cell protein) ${ }^{-1}$ at $0.5 \mathrm{~h}^{-1}$ [107]. So it appears likely that fermentation of glycogen in cyanobacteria primarily serves maintenance purposes because it does not aim to sustain growth [62]. This view is in accordance with the low specific activities of the key enzymes of the fermentation metabolism that are found in cell-free extracts $[22,37,60,61,63]$. Most of the fermentation experiments have been conducted with resting cell suspension in buffers which would not allow growth. However, in those cases where cells were incubated in complete medium, indeed no growth was detected $[44,62]$.

From the degradation rates of glycogen and the pathways likely to be involved, the ATP production during fermentation is estimated to be in the range of $0.8-8.5 \mathrm{nmol} \mathrm{min}{ }^{-1}$ (mg cell protein) $)^{-1}$ (Table 7). It must be emphasized, however, that these numbers 
do not take into account that substrates other than glycogen may be involved in fermentation as well. For instance, in $O$. limosa the osmoprotectant trehalose is fermented as well [63] and the glucose part of glucosyl-glycerol, the osmoprotectant of $M$. chthonoplastes is fermented when this organism contains low amounts of glycogen [61]. Moreover, Microcystis PCC7806 [22], Nostoc strain Cc [62] and O. terebriformis [28] can also utilize exogenous glucose.

Data on maintenance requirements of cyanobacteria are scarce. Only for one organism, O. agardhii, has this been examined thoroughly [106]. Whereas the specific maintenance rate is independent of the light intensity, the efficiency with which radiant energy is converted into biochemical energy decreases with increasing light intensity. At the lowest light intensity tested the specific light energy uptake for maintenance is estimated to equal a rate of ATP

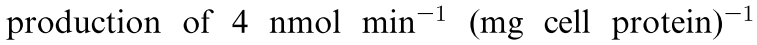
(see Appendix A). Although this value already agrees reasonably well with the data obtained from fermentation experiments, the true specific ATP production for maintenance may be even lower at lower light intensity. In the following sections the energetics of fermentation in four cyanobacteria that have been studied in reasonable detail is considered.

\subsection{Energetics of fermentation in Oscillatoria limnetica}

Oren and Shilo [44] were the first to report anaerobic dark metabolism in a cyanobacterium. Their choice to study $O$. limnetica, a strain isolated from Solar Lake (Sinai desert), was based on the fact that this organism in its natural habitat thrives for prolonged periods of time under anoxic conditions. $O$. limnetica is also capable of anoxygenic photosynthesis, using sulfide as electron donor, which is oxidized to elemental sulfur and excreted from the cells [49]. Oren and Shilo [44] demonstrated that O. limnetica was capable of degrading of endogenous carbohydrate and excreting lactate. In the presence of elemental sulfur, sulfide was produced while the amount of lactate produced decreased. Lactate was the only organic fermentation product produced by O. limnetica.

In the absence of elemental sulfur $O$. limnetica produced $1.6 \mathrm{~mol}$ of lactate per glucose metabolized.
During homolactic acid fermentation lactate is the only fermentation product and also no $\mathrm{CO}_{2}$ is produced. This means that the carbon recovery was only $80 \%$. For each molecule of glycogen-glucose that is fermented to 2 molecules lactate 3 ATP are generated. Thus this fermentation would have resulted in the formation of $2.4 \mathrm{~mol}$ of ATP $(0.8 \times 3)$ for each molecule of glycogen-glucose degraded. Assuming that the carbon not recovered has been assimilated in structural cell material (C-content is $50 \%$ ) and that $\mathrm{Y}_{A T P}$ equals $20 \mathrm{~g}$ biomass (mol ATP) $)^{-1}$, it can be calculated that $1.44 \mathrm{~mol}$ of ATP are required to produce this cell material. Thus $0.96 \mathrm{~mol}$ of ATP would be available for maintenance purposes, which is $40 \%$ of the ATP generated. In order to judge how much this would be in terms of biomass and rate the $q_{\mathrm{ATP}}$ has to be known.

Oren and Shilo [44] calculated a rate of polyglucose utilization of about $5 \mu \mathrm{mol}$ glucose (mg chlorophyll $a)^{-1} \mathrm{~h}^{-1}$ in the presence of elemental sulfur. They did not give a value for the degradation in the absence of elemental sulfur but this might have been the same or lower. In order to obtain a protein-based $q_{\mathrm{ATP}}$ the ratio protein:chlorophyll $a$ has to be known. O. limnetica contains about $2 \mu \mathrm{mol}$ glucose equivalents (mg cell protein) $)^{-1}$ which is utilized in about $20 \mathrm{~h}$ of dark anaerobic incubation. From these data it can be calculated that the ratio protein:chlorophyll in $O$. limnetica must have been about 50 . This is about twice as high as for $M$. chthonoplastes [61] or $O$. limosa [108]. However, the relatively low content of chlorophyll $a$ in $O$. limnetica may have been due to the anoxygenic conditions under which the organism was grown with high light intensity $\left(2 \times 10^{-3} \mathrm{~J} \mathrm{~cm}^{-2} \mathrm{~s}^{-1}\right)$ and sulfide present. This gives a specific rate of glucose utilization of $1.7 \mathrm{nmol}$ $\min ^{-1}(\mathrm{mg} \text { cell protein })^{-1}$. The $q_{\mathrm{ATP}}$ is $4 \mathrm{nmol}$ $\min ^{-1}(\mathrm{mg} \text { cell protein })^{-1}(80 \%$ of the glucose utilized is fermented). Since $40 \%$ of the ATP generated is available for maintenance, the

$q_{\mathrm{ATP}}^{\mathrm{m}}$

is estimated to be $1.6 \mathrm{nmol} \mathrm{min}^{-1}$ (mg cell protein $)^{-1}$. However, this number may be considerably lower when the rate of glucose degradation is lower in the absence of elemental sulfur.

Another interesting observation made by Oren and Shilo [44] was that in the presence of the inhib- 
itor of protein synthesis, chloramphenicol, the amount of lactate produced per glucose metabolized increased to 1.9 which was almost the amount that would be expected when the glucose was completely fermented to lactate. This also strongly indicated that growth can occur during dark anaerobic incubation. Oren and Shilo [44], who used a $\mathrm{Y}_{A T P}$ of $10.5 \mathrm{~g}$ biomass (mol ATP) ${ }^{-1}$ but did not take into account a specific rate of maintenance energy requirement, also calculated that about $20 \%$ of polyglucose could have been assimilated into structural cell material. This would have resulted in an increase of biomass of only $3.3 \%$. It is not correct not to include the rate of maintenance energy requirement in these calculations because it is a substantial part of the energy generated under dark anoxic conditions. On the other hand a $\mathrm{Y}_{A T P}$ of 20 is probably more realistic than $10.5 \mathrm{~g}$ biomass $(\mathrm{mol} \mathrm{ATP})^{-1}$ [109].

Oren and Shilo [44] argued that it would not make a big difference if sulfide respiration would occur. They assumed that 3.5 ATP could be generated per glucose oxidized which is only 0.5 more than in the case of lactate fermentation. In the presence of elemental sulfur the carbon recovery of dark anaerobic metabolism in $O$. limnetica was $92 \%$. Even with elemental sulfur present some lactate was produced. Per molecule of glucose $0.8 \mathrm{~mol}$ lactate and $6.2 \mathrm{~mol}$ sulfide are produced. In order to produce $6.2 \mathrm{~mol}$ sulfide $0.52 \mathrm{~mol}$ glucose must be oxidized. Add the 0.4 mol glucose that was fermented to lactate, only 0.08 mol of the glucose could have been assimilated into structural cell material. With $50 \%$ carbon content this would give an increase in structural cell material of $11.52 \mathrm{~g}$ and with a $\mathrm{Y}_{A T P}$ of $20 \mathrm{~g}$ biomass (mol ATP $)^{-1}$, this would cost 0.58 ATP. This could easily be produced by lactate fermentation. The $0.4 \mathrm{~mol}$ glucose fermented to lactate would have yielded 1.2 ATP. The specific rate of glucose utilization is 1.7 nmol $\min ^{-1}$ (mg cell protein $)^{-1}$, of which $40 \%$ is diverted to lactate fermentation. Assuming ATP generation exclusively through lactate fermentation the

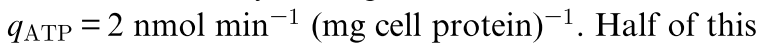
ATP production is required for the assimilation of carbon into structural cell material. This leaves a $q_{\mathrm{ATP}}^{\mathrm{m}}=1 \mathrm{nmol} \mathrm{min}^{-1}(\mathrm{mg} \text { cell protein })^{-1}$. These specific rates of maintenance energy requirements seem very reasonable when compared with what was cal- culated for the other cyanobacteria. Whether the reduction of elemental sulfur is associated with energy generation is still uncertain. The oxidation of glucose through the OPP pathway does not yield any ATP and therefore a role of sulfur solely as electron sink would represent a loss of energy.

\subsection{Energetics of fermentation in Oscillatoria limosa}

$O$. limosa is a non-heterocystous nitrogen-fixing cyanobacterium. Heyer et al. [63] suggested that fermentation in $O$. limosa, in addition to meeting maintenance requirements, might support other metabolic processes such as growth and nitrogen fixation. Stal and Heyer [105] have demonstrated that this organism was capable of dark anaerobic acetylene reduction (nitrogenase activity) for $12-24 \mathrm{~h}$ at a rate of $2 \mu \mathrm{mol} \mathrm{C}_{2} \mathrm{H}_{2} \mathrm{~h}^{-1}$ (mg chlorophyll $\left.a\right)^{-1}$. The ratio protein:chlorophyll $a$ in this organism is 23 [108] which transforms this rate of acetylene reduction to 1.45 $\mathrm{nmol} \mathrm{min}^{-1}$ (mg cell protein $)^{-1}$. Reduction of dinitrogen by nitrogenase requires 4 ATP for each pair of electrons involved (16 ATP per $\mathrm{N}_{2}$ ) [110]. This means that the reduction of one molecule $\mathrm{C}_{2} \mathrm{H}_{2}$ to $\mathrm{C}_{2} \mathrm{H}_{4}$ (ethylene) would require 4 ATP (assuming the same mechanism as for $\mathrm{N}_{2}$ reduction). To support the observed rate of dark anaerobic acetylene reduction $5.8 \mathrm{nmol}$ ATP $\min ^{-1}(\mathrm{mg} \text { cell protein })^{-1}$ are required. Fermentation of glycogen in nitrogen-fixing $O$. limosa yields $2.2 \mathrm{nmol}$ ATP $\min ^{-1}$ (mg cell protein $)^{-1}$ (Table 7). However, this organism also ferments its osmoprotectant trehalose via the homoacetic pathway [63]. The homoacetic fermentation of glucose results in a net yield of 4 ATP (Fig. 2). The net yield of ATP produced during the formation of acetate from $\mathrm{CO}_{2}$ is zero (Fig. 2). However, energy from this reaction may be conserved electrochemically, e.g. as a $\mathrm{Na}^{+}$gradient [72], which would presumably add another equivalent of ATP. Although only $8 \mu \mathrm{mol}(\mathrm{mg} \text { chlorophyll } a)^{-1}$ of the disaccharide trehalose are degraded in $24 \mathrm{~h}$, the high energy yield of homoacetate fermentation more than doubles the $q_{\text {ATP }}$ to $4.6 \mathrm{nmol} \mathrm{m^{-1 }}$ (mg cell protein $)^{-1}$. This is obviously not sufficient to explain the observed rate of acetylene reduction. The possibility that $q_{\mathrm{ATP}}$ is underestimated should be considered. For instance, the transport of acetic and lactic acid over the cytoplasmic membrane may generate metabolic energy 
[111]. If this possibility is considered we estimate a $q_{\text {ATP }}$ of 6.1 . This would be sufficient to support the observed rate of acetylene reduction but leaves hardly any ATP for other metabolic processes (e.g. maintenance). The carbon and redox balances of fermentation in $O$. limosa were good, which indicated that no carbon was used for biosynthesis.

\subsection{Energetics of fermentation in Microcystis aeruginosa}

Moezelaar and Stal [37] found that the glycogen content of Microcystis PCC7806 (M. aeruginosa) depended on the light regime under which it was cultivated. When the organism was grown under an alternating light-dark $(16-8 \mathrm{~h})$ cycle the maximum amount of glycogen (at the end of the light phase) was $1.5 \mu \mathrm{mol}$ glucose (mg cell protein $)^{-1}$. Under continuous light this organism contained twice as much glycogen $\left(3 \mu \mathrm{mol}\right.$ glucose $\left.(\mathrm{mg} \text { cell protein })^{-1}\right)$. The fermentation patterns of both cultures showed marked differences. Whereas fermentation in the light-dark grown culture had a reasonable carbon balance $(86 \%)$ and a good oxidation/reduction $(\mathrm{O} /$ R) balance (1.03) [22], this was not the case in the culture grown in continuous light (carbon recovery $59 \%, \mathrm{O} / \mathrm{R}$ balance 1.56) [37,112] (Table 8). The carbon balance is the amount of carbon atoms $(\mu \mathrm{mol})$ in the substrate(s) which is (are) metabolized, divided by the amount of carbon atoms recovered in the products, times $100 \%$. The carbon balance should be $100 \%$ and a lower value indicates that products may be missing. The $\mathrm{O} / \mathrm{R}$ balance is the sum of all oxidized substrates and products, divided by the sum of all reduced substrates and products. Each compound receives a redox number which indicates the number of $\mathrm{H}$ atoms in the compound deviating from water (which therefore has the redox number 0). Excess of $\mathrm{H}$ atoms gives a negative redox number, a shortage is indicated by a positive sign. The redox numbers are multiplied by the molar amount of the substrate used or product formed. The $\mathrm{O} / \mathrm{R}$ balance should be 1 . A greater value indicates a lack of reduced compounds. Furthermore the light-dark grown culture produced much more ethanol relative to acetate as compared to the culture grown in continuous light. The latter produced approximately equimolar amounts of ethanol and acetate. In addi-
Table 8

Stoichiometry of glycogen degradation and product formation during fermentation in Microcystis PCC7806

\begin{tabular}{llll}
\hline & & L cells & L-D cells \\
\hline Substrate & glucose (glycogen) & 8.9 & 3.5 \\
Products & ethanol & 5.3 & 4.9 \\
& acetate & 4.9 & 1.1 \\
& $\mathrm{H}_{2}$ & 2.5 & 1.8 \\
& $\mathrm{CO}_{2}$ & 10.2 & 6.0 \\
& L-lactate & 0.3 & $\mathrm{nd}$ \\
C recovery & & $59 \%$ & $86 \%$ \\
O/R balance & & 1.56 & 1.03 \\
\hline
\end{tabular}

Washed cells $\left(10 \mathrm{ml}, 2.0 \mathrm{mg}\right.$ protein $\left.\mathrm{ml}^{-1}\right)$ were incubated in a 30 $\mathrm{ml}$ serum bottle under an argon atmosphere for $8 \mathrm{~h}$. The cells were grown in batch culture under continuous light (L) or under an alternating light-dark (16-8 h) cycle (L-D) and harvested at $\mathrm{OD}_{750}$ 0.8-1.0. Amounts of substrate and products are expressed in $\mu$ mol. $\mathrm{C}$ balance is the amount of carbon atoms ( $\mu \mathrm{mol})$ in the substrate(s) which is (are) metabolized, divided by the amount of carbon atoms recovered in the products, times $100 \%$. The $\mathrm{C}$ balance should be $100 \%$ and a lower value indicates that products may be missing. The $\mathrm{O} / \mathrm{R}$ balance is the sum of all oxidized substrates and products, divided by the sum of all reduced substrates and products. Each compound receives a redox number which indicates the number of $\mathrm{H}$ atoms in the compound deviating from water (which therefore has the redox number 0). Excess of $\mathrm{H}$ atoms gives a negative redox number, a shortage is indicated by a positive sign. The redox numbers are multiplied by the molar amount of the substrate used or product formed. The O/R balance should be 1 . A greater value indicates a lack of reduced compounds. Data from [22,37].

tion, the culture grown under continuous light also produced some lactate which was not the case in the light-dark grown cells. These differences could not be attributed to differences in specific activities of enzymes involved in fermentation since these were identical in both cultures and sufficient to explain the highest rates of product formation. The rates of glycogen degradation in the light-dark and the continuous light grown cultures were 0.4 and 0.9 nmol glucose $\min ^{-1}$ (mg cell protein $)^{-1}$, respectively.

In the culture of Microcystis PCC7806 grown under a light-dark regime the carbon recovery was $86 \%$ and the $\mathrm{O} / \mathrm{R}$ balance 1.03 [22] (Table 8). Assuming that the missing carbon had been converted into cell material which of course would result in $100 \%$ carbon recovery, the $\mathrm{O} / \mathrm{R}$ balance becomes 0.99 . Reassimilation of carbon from glycogen could proceed via acetyl-CoA [1] which might explain the relative low amount of acetate produced by this culture. Cell material is slightly reduced and a redox number of 
$-0.37(\mathrm{~mol} \mathrm{C})^{-1}$ is calculated on the basis of atomic ratios of phytoplankton given by Atkinson and Smith [113]. The amount of ATP produced during fermentation in this culture can be calculated taking into account the amount of glucose converted into fermentation products $(3 \mu \mathrm{mol}$, Table 8$)$. Three ATP are produced per glycogen-glucose fermented and 1 for each acetate produced. This gives a total amount of ATP of $10.2 \mu \mathrm{mol}$ and a $q_{\text {ATP }}$ of $1 \mathrm{nmol} \mathrm{min}-1$ $(\mathrm{mg} \text { cell protein })^{-1}$, which is slightly lower than indicated in Table 7 where it was based on the decrease of glycogen rather than on the formation of fermentation products. The carbon that was not recovered ( $3 \mu \mathrm{mol}$ ) could give rise to $72 \mu \mathrm{g}$ cell material (assuming $50 \%$ of cell material is carbon). Its synthesis would cost $3.6 \mu \mathrm{mol}$ ATP, assuming a $\mathrm{Y}_{A T P}$ of $20 \mathrm{~g}$ biomass (mol ATP) $)^{-1}$, which is considered as realistic value in this case [109]. It is assumed that the remaining $6.6 \mu \mathrm{mol}$ ATP (10.2-3.6) covers the requirements for maintenance. It equals $0.7 \mathrm{nmol}$ ATP $\min ^{-1}$ (mg cell protein $)^{-1}$. This rate seems low but it is in the range of the theoretical value calculated for Escherichia coli $\left(0.5 \mathrm{nmol}\right.$ ATP $\mathrm{min}^{-1} \quad$ (mg protein $)^{-1}$ ) [109]. Measured rates of maintenance energy in E. coli are 10-100 times this theoretical rate [109] but cyanobacteria are known for their low maintenance requirements [106]. The $q_{\mathrm{ATP}}^{\mathrm{m}}$ of 0.7 nmol $\min ^{-1}$ (mg cell protein $)^{-1}$ is still more than 5 times lower than calculated for $O$. agardhii (see Appendix A). However, the $q_{\mathrm{ATP}}^{\mathrm{m}}$ of 4 for this organism was calculated for growth in the light and it is known that the $q_{\mathrm{ATP}}^{\mathrm{m}}$ increases with light intensity. The $q_{\mathrm{ATP}}^{\mathrm{m}}$ of 0.7 we have derived seems therefore a good estimate for maintenance energy in cyanobacteria thriving under anaerobic conditions in the dark. It is therefore reasonable to apply this value also for the culture of Microcystis PCC 7806 grown under continuous light. If we assume the missing carbon from fermentation in this organism also to be converted in cell material in order to make up the carbon balance to $100 \%$ it makes the $\mathrm{O} / \mathrm{R}$ balance only slightly better (1.35). This high $\mathrm{O} / \mathrm{R}$ balance is most probably caused by an erroneous value for $\mathrm{CO}_{2}$. On the basis of the fermentation pathway [22] one $\mathrm{CO}_{2}$ is produced for each molecule ethanol and acetate produced. Moezelaar and Stal [37] hypothesized that some re-fixation of $\mathrm{CO}_{2}$ via the carboxylation of phosphoenolpyruvate had occurred: phosphoenolpyruvate $+\mathrm{CO}_{2}+\mathrm{H}_{2} \mathrm{O} \rightarrow$

oxaloacetate $+\mathrm{P}_{\mathrm{i}}$

PEP carboxylase, the enzyme that catalyzes this reaction, is a very important enzyme for $\mathrm{CO}_{2}$ metabolism in cyanobacteria. The activity of this enzyme results in the synthesis of $\mathrm{C} 4$ products. It has been estimated that in cyanobacteria up to $20 \%$ of carbon assimilation can be attributed to PEP carboxylase [114].

If only 1.5 of the $6.5 \mu \mathrm{mol} \mathrm{CO}_{2}$ were re-fixed during fermentation both the $\mathrm{C}$ and $\mathrm{O} / \mathrm{R}$ balances are satisfied (Table 9). The fixation of this amount of $\mathrm{CO}_{2}$ via the carboxylation of phosphoenolpyruvate would cost $1.5 \mu \mathrm{mol}$ ATP. When taking into account

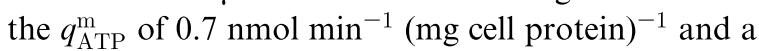
$\mathrm{Y}_{A T P}$ of $20 \mathrm{~g}$ biomass (mol ATP) ${ }^{-1}$, sufficient energy is available for the synthesis of $180 \mu \mathrm{g}$ structural cell material (assuming $50 \%(\mathrm{w} / \mathrm{w})$ of cell matter is carbon). This fits the $7.2 \mu \mathrm{mol} \mathrm{C}$ (equals $172 \mu \mathrm{g}$ cell material) that must have been assimilated (Table 9).

Some of the assumptions used above were rather conservative. For instance, $\mathrm{Y}_{A T P}$ normally includes energy for maintenance purposes. Furthermore, no energy for the transport of substrate is necessary since the glucose is already inside the cell. Moreover, many cyanobacteria contain the polypeptide cyanophycin (multi-L-arginyl poly-L-aspartate) [69] which can provide the cell with ready to use amino acids for biosynthesis. The excretion of acids such as acetate and lactate may also yield energy [111]. We conclude that even though the $q_{\mathrm{ATP}}$ seems rather low, fermentation of endogenous carbohydrate storage may support a limited amount of growth in cyanobacteria. However, due to the limited amount of storage carbohydrate this would not result in a measurable increase of biomass. This conclusion sheds some light on the fermentation in $M$. chthonoplastes.

\subsection{Energetics of fermentation in Microcoleus chthonoplastes}

The glycogen content in $M$. chthonoplastes may vary with culture conditions as in Microcystis. Cells from the exponential growth phase contained relatively low amounts of glycogen $(0.3 \mu \mathrm{mol}$ glucose $(\mathrm{mg} \text { cell protein })^{-1}$ ) whereas cells from the stationary 
Table 9

Stoichiometry of fermentation of endogenous glucose (glycogen) in a culture of the cyanobacterium Microcystis aeruginosa PCC7806 grown under continuous light

\begin{tabular}{|c|c|c|c|c|}
\hline Compound & $\mu \mathrm{mol}$ & $\mu \mathrm{mol} \mathrm{C}$ & Redox number & Redox value \\
\hline Glucose & 4.3 & -25.8 & 0 & 0 \\
\hline Ethanol & 3.5 & +7.0 & -4 & -14 \\
\hline Acetate & 3.0 & +6.0 & 0 & 0 \\
\hline $\mathrm{H}_{2}$ & 1.6 & 0 & -2 & -3.2 \\
\hline $\mathrm{CO}_{2}$ & 5.0 & +5.0 & +4 & +20 \\
\hline Cell carbon & 7.2 & +7.2 & $-0.37^{\mathrm{a}}$ & -2.7 \\
\hline \multirow[t]{2}{*}{ Lactate } & 0.2 & +0.6 & 0 & 0 \\
\hline & & $+25.8 /-25.8$ & & $+20 /-19.9$ \\
\hline Balance & & $100 \%$ & & 1.01 \\
\hline
\end{tabular}

The numbers in italics are calculated (see text), the other amounts were measured [37]. Incubation $6 \mathrm{~h}$, total biomass $15 \mathrm{mg}$ protein.

${ }^{\text {a }}$ Per $\mu \mathrm{mol} \mathrm{C}$.

growth phase contained significantly larger amounts $\left(2 \mu \mathrm{mol}\right.$ glucose $\left.(\mathrm{mg} \text { cell protein })^{-1}\right)$ [61]. This huge difference in glycogen content had only a moderately effect on the specific rate of glucose fermentation. This rate was $0.40 \mathrm{nmol}$ glucose $\mathrm{min}^{-1}$ (mg cell protein $)^{-1}$ in the stationary phase cells and 0.33 nmol glucose $\min ^{-1}$ (mg cell protein $)^{-1}$ in the exponentially growing cells. This was partly caused by the fact that the low glycogen containing cells also degraded the osmoprotectant glucosyl-glycerol. Only the glucose of this compound was utilized and glycerol was excreted into the medium. The degradation of glucosyl-glycerol contributed $0.12 \mathrm{nmol}$ glucose $\min ^{-1}$ (mg cell protein $)^{-1}$ to the rate of glucose fermentation, leaving $0.21 \mathrm{nmol}$ glucose $\min ^{-1}$ (mg cell protein $)^{-1}$ for the degradation of glycogen. This is about half the rate of glycogen degradation of the stationary phase cultures. The latter cultures did not degrade the osmoprotectant glucosyl-glycerol. In fact, the glycogen content of stationary phase cultures and the rate with which it is decomposed would allow the organism to continue for 3.5 days. We have indeed observed that $M$. chthonoplastes survived 4-5 days of incubation under dark anoxic conditions before it started to lyse. Due to rather similar $q_{\text {glucose }}$ in both cultures the $q_{\text {ATP }}$ were also quite comparable in both cultures: 1.65 and $1.32 \mathrm{nmol} \mathrm{\textrm {min } ^ { - 1 }}$ $(\mathrm{mg} \text { cell protein })^{-1}$ in the stationary and exponential phase cultures, respectively.

The fermentation patterns showed good carbon recoveries but rather poor $\mathrm{O} / \mathrm{R}$ balances of 1.55 and 1.22 in the exponential and stationary phase cultures, respectively [61]. The stationary phase cul- ture also showed a larger amount of acetate formed than expected on the basis of the fermentation pathway. Moezelaar et al. [61] supposed that a homoacetic fermentation pathway existed in $M$. chthonoplastes in addition to the mixed acid fermentation. However, attempts to detect the key enzymes of the homoacetic pathway failed [61]. Moreover, the assumption of the presence of homoacetic fermentation improved the $\mathrm{O} / \mathrm{R}$ balance not sufficiently (the $\mathrm{O} / \mathrm{R}$ balance decreased from 1.51 to 1.22 ). In order to explain these high $\mathrm{O} / \mathrm{R}$ balances of fermentation in M. chthonoplastes Moezelaar et al. [61] assumed that ferric iron could have served as electron acceptor. They conceived that part of the formic acid is oxidized to $\mathrm{CO}_{2}$ by ferric iron according to the following equation [115]:

$\mathrm{HCOO}^{-}+2 \mathrm{Fe}^{3+} \rightarrow \mathrm{CO}_{2}+\mathrm{H}^{+}+2 \mathrm{Fe}^{2+}$

M. chthonoplastes was grown with an elevated amount of ferric-citrate in the medium because it resulted in homogeneous growth of this organism [61]. Similarly, the reduction of ferric iron could also (in part) explain the high $\mathrm{O} / \mathrm{R}$ balance of 1.30 in the case of fermentation in the presence of elemental sulfur [61]. With elemental sulfur present a reduction to sulfide will take place. However, sulfide will be oxidized back to elemental sulfur by ferric iron [115] (see equation on p. 23). Thus, the amount of sulfide formed will be underestimated.

Recently, we have investigated the possibility of ferric iron reduction by cultures of $M$. chthonoplastes. It was shown that Eq. 2 was indeed carried 
out by this cyanobacterium [76]. However, the rates at which it occurred were far from sufficient to serve as an important electron acceptor in fermentation and taking iron reduction into account would have only a minor influence on the $\mathrm{O} / \mathrm{R}$ balance of fermentation in $M$. chthonoplastes.

In the light of what has been calculated for Microcystis PCC7806 it may be hypothesized that also in M. chthonoplastes some re-assimilation of $\mathrm{CO}_{2}$ could have take place. According to the proven fermentation pathway in this organism [61] the amount of $\mathrm{CO}_{2}$ produced must equal the sum of the amounts of ethanol and acetate, minus the amount of formate. Moreover, the amount of $\mathrm{CO}_{2}$ should equal the amount of $\mathrm{H}_{2}$. From Table 10 it is clear that this was not the case. It is assumed that the missing $\mathrm{H}_{2}$ had been used for the synthesis of structural cell material. This amount can be calculated as to equal the sum of the amounts of ethanol and acetate minus the amounts of formate and $\mathrm{H}_{2}$. The amount of reassimilated $\mathrm{CO}_{2}$ can than be calculated as half of the molar amount of the missing $\mathrm{H}_{2}$ (assuming $\mathrm{CH}_{2} \mathrm{O}$ as the formula for structural cell material). From the calculated amounts of $\mathrm{CO}_{2}$ reassimilated and cell material produced, reasonable carbon recoveries and $\mathrm{O} / \mathrm{R}$ balances are obtained for both the exponential (low glycogen) and stationary (high glycogen) cultures (Tables 10 and 11).

The deviations from the ideal $\mathrm{O} / \mathrm{R}$ balance of 1 may be found in a possibly too high value for the reduced state of structural cell material and because the reduction of iron was not included in these calculations. Formate-mediated iron reduction may have been more important in the stationary phase culture because of the much higher production of formate in that culture. Iron reduction in $M$. chthonoplastes has a rather low affinity for formate.

The ATP yield of fermentation in $M$. chthonoplastes can be calculated as follows. For every glucose degraded 3 ATP are formed and 1 additional for each acetate produced. We calculated the amount of glucose degraded as half of the sum of the amounts of ethanol, acetate and lactate formed. This gives 28.8 and $84.8 \mu \mathrm{mol}$ ATP for the low and high glycogen containing cultures, respectively. Assuming $\mathrm{CO}_{2}$ assimilation by carboxylation of phosphoenolpyruvate (see above) (which would cost 1 ATP $\left.\left(\mathrm{CO}_{2}\right)^{-1}\right), \mathrm{Y}_{A T P}$ of $20 \mathrm{~g}$ biomass (mol ATP $)^{-1}$, and a carbon content of $50 \%$ of cell dry weight it is calculated that 1.39 and $0.88 \mathrm{nmol}$ ATP $\min ^{-1}$ (mg cell protein $)^{-1}$ are available for maintenance purposes in the stationary phase and exponentially growing culture, respectively. These numbers are well above what was calculated for $\mathrm{Mi}$ crocystis. Thus, from an energetic point of view the assumed re-assimilation of $\mathrm{CO}_{2}$ would be possible. It would result in an increase of cell protein of 79 and $53 \mu \mathrm{g}$ (assuming $50 \%$ of cell material is protein) in the stationary phase and exponential culture, respectively. This increase is very small on a total protein content of respectively 35 and $15 \mathrm{mg}$.

Notwithstanding the fact that the stationary phase culture of $M$. chthonoplastes contained almost seven times as much glycogen as the exponentially growing culture, this resulted hardly in a higher rate of fermentation and supposed increase in biomass. In part this was due to the fact that the exponentially growing culture also utilized its osmoticum glucosyl-glyc-

Table 10

Stoichiometry of fermentation of endogenous glucose (glycogen and glucosyl-glycerol) in an exponentially growing (low glycogen) culture of the cyanobacterium Microcoleus chthonoplastes

\begin{tabular}{|c|c|c|c|c|}
\hline Compound & $\mu \mathrm{mol}$ & $\mu \mathrm{mol} \mathrm{C}$ & Redox number & Redox value \\
\hline Ethanol & 7.4 & 14.8 & -4 & -29.6 \\
\hline Formate & 5.1 & 5.1 & +2 & +10.2 \\
\hline $\mathrm{H}_{2}$ & 0.6 & 0 & -2 & -1.2 \\
\hline $\mathrm{CO}_{2}$ & 5 & 5 & +4 & +20 \\
\hline Balance & & $102 \%$ & & 0.93 \\
\hline
\end{tabular}

The numbers in italics are calculated (see text), the other amounts were measured [61]. Incubation $24 \mathrm{~h}$, total biomass $15 \mathrm{mg}$ protein. 
Table 11

Stoichiometry of fermentation of endogenous glucose (glycogen) in a stationary phase (high glycogen) culture of the cyanobacterium $\mathrm{Mi}$ crocoleus chthonoplastes

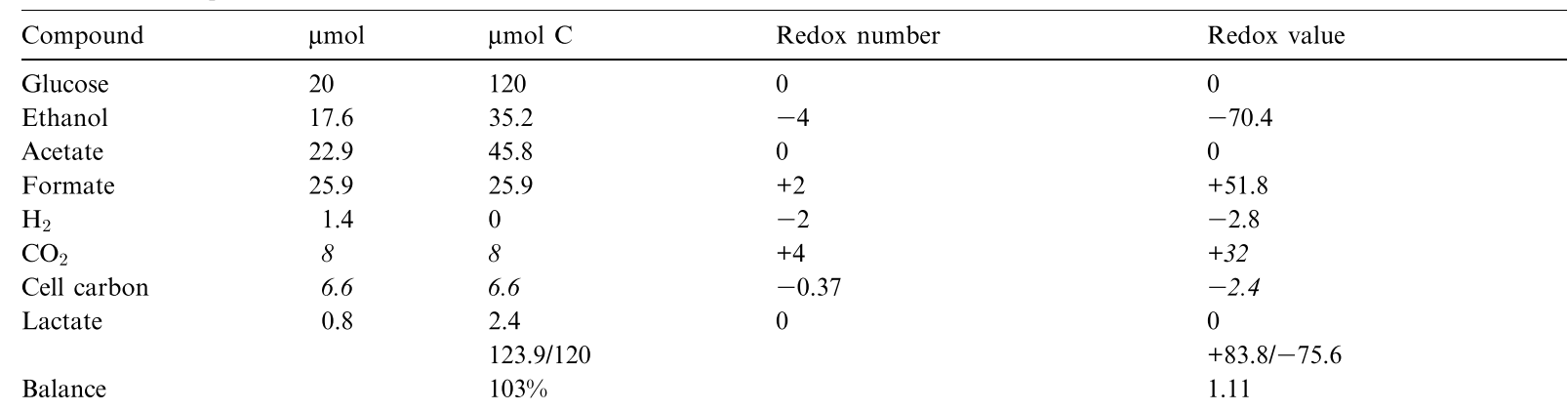

The numbers in italics are calculated (see text), the other amounts were measured [61]. Incubation $24 \mathrm{~h}$, total biomass $35 \mathrm{mg}$ protein.

erol. Apparently, a faster growth was not possible. Although the fermentation experiments were carried out in a nutrient-free buffer, it can be assumed that sufficient nutrients for growth must have been present in the cells or as contaminants in the buffer. Growth of cyanobacteria under anaerobic conditions is not trivial. For instance, notwithstanding the fact that $M$. chthonoplastes can perform sulfide-dependent anoxygenic photosynthesis and fermentation it is not capable of growth in the complete absence of oxygen. Oxygen appears to be an essential nutrient for this organism [116]. On the other hand the activity of certain enzymes may have limited faster degradation of glycogen, although the measured enzyme activities of the mixed acid fermentation in $M$. chthonoplastes were sufficient to explain the rates of product formation. The formation of lactate in the high glycogen containing culture hinted to an overflow metabolism caused by high intracellular concentrations of fructose-1,6-bisphosphate and/or pyruvate [75]. Relative to acetate the low production of ethanol in this culture may be explained by the low specific activity of alcohol dehydrogenase relative to acetate kinase [61]. Whatever caused the limited rate of glycogen degradation it is likely to be responsible for the higher rest (maintenance) rate of ATP production of $1.39 \mathrm{nmol} \mathrm{m^{-1 }}(\mathrm{mg} \text { cell protein })^{-1}$. The rest (maintenance) rate of the low glycogen containing culture is with 0.88 slightly higher than the one derived for Microcystis. The fact that this culture degrades part of its osmoticum glucosyl-glycerol may cost the organism some additional energy in order to maintain osmotic equilibrium [67].
The limited rate of glycogen degradation in $M$. chthonoplastes may serve an important ecological goal. It has been shown that this organism can survive 4-5 days under anoxic conditions in the dark. In microbial mats, the environment in which $M$. chthonoplastes occurs anoxic dark conditions may persist for prolonged periods of time, particularly during periods of increased rates of deposition. The importance of a low rate of glycogen degradation can be exemplified by the case of $O$. terebriformis. Under aerobic conditions in the dark this organism depletes its energy storage quickly after which it dies. However, under anoxic conditions glycogen is degraded much slower, allowing the organism to survive the night period [28]. In fact, in order to prevent aerobic (and fast) degradation of glycogen this organism moves into the anoxic part of the sediment during the dark [117].

\section{Concluding remarks}

Most of the research on cyanobacteria concentrates on their photoautotrophic mode of life. This, however, does not give credit to the fact that these organisms are frequently faced with situations in which light is not available. This is not only the case during the night but also during the daytime cyanobacteria may be deprived of light and some symbiotic species live permanently in the dark. In order to survive short periods of darkness cyanobacteria use endogenous carbohydrate (glycogen) which is synthesized and stored in the light. 
Glycogen is mobilized via the OPP pathway and under aerobic conditions respiration may yield sufficient energy to allow growth. A few species are even capable of taking up a limited number of organic compounds (mainly glucose, fructose and sucrose) and grow chemoorganotrophically in the dark. Very little work has been done on the chemoorganotrophic metabolism of cyanobacteria under anoxic conditions. Cyanobacteria exposed in their natural environment to anoxic dark conditions possess the capacity to ferment endogenous storage carbohydrate and some species can even take up exogenous carbohydrate. The marine mat-forming cyanobacteria $O$. limosa and $M$. chthonoplastes also partly degraded their organic solutes that serve as osmoprotectants in these organisms. In $M$. chthonoplastes the degradation of osmoprotectant is particularly important when the amount of glycogen is low. It is not clear how osmotic equilibrium of the cell is maintained when the organic solute is degraded, but it is assumed that inorganic ions (probably $\mathrm{K}^{+}$) are temporarily taking over this function. Although the maintenance of osmotic equilibrium by potassium ions would take energy, the energy content of the organic osmoprotectant is apparently of such importance for the organism that its mobilization is essential for dark anaerobic energy generation and weighs more than its function as maintaining osmotic equilibrium. The consequences of the catabolic degradation of the osmoprotectant in cyanobacteria deserves further study, both with regard of the precise mechanism of the achievement of osmotic equilibrium under anoxic dark conditions and its energetics.

The cyanobacteria capable of fermentation show a variety of different pathways. These include homoand heterolactic acid fermentation, homoacetic acid fermentation and mixed acid fermentations. In a few species the pathways have been established by the identification of the enzymes. In all species investigated the fermentation pathways appeared to be constitutive. All enzymes were present in photoautotrophically grown cells. When cell suspensions were transferred to dark anoxic conditions fermentation commenced without a lag. Pre-incubation in the dark or under anoxic conditions did not increase enzyme activities or changed the rate of fermentation. Also the addition of inhibitors of protein syn- thesis does not prevent fermentation. The constitutive property of fermentation has the advantage for the organism that it can react immediately when anoxic conditions are established, which may occur within minutes in some environments. On the other hand it can be asked how fermentation is regulated. In $O$. limnetica the inhibition of aerobic respiration by cyanide was sufficient to start fermentation and in symbiotic Nostoc sp. fermentation did not even require completely anoxic conditions and started at low levels of oxygen. Thus neither light nor oxygen has a negative regulatory effect on fermentation in these cyanobacteria. From the results obtained thus far it is clear that in none of the cyanobacteria studied fermentation is regulated at the level of expression of genes. It is possible that the fermentation pathways in these cyanobacteria are regulated (activated or inhibited) by a particular metabolite. This was for instance the case with lactate dehydrogenase in Microcystis PCC 7806 (see Section 4). This type of regulation should also be present when (part of) the pentose phosphate pathway is involved as is the case in heterolactic fermentation in $O$. limosa. Metabolic control must ensure that the reductive pentose phosphate cycle operates only in the light and the oxidative process in the dark. However, in the majority of cyanobacterial fermentations the EMP pathway is involved and therefore the possibility that fermentation in these cyanobacteria is not subject to regulation and is itself constitutive cannot be excluded. This would mean that in this case a small part of the carbon fixed during the light is lost by fermentation. Another observation that supports this is the fact that $M$. chthonoplastes reduces ferric iron in the light as well as in the dark, both under aerobic and anoxic conditions at the same rate. The reduction of ferric iron was shown to be enzyme catalyzed and coupled to the oxidation of the fermentation product formate [76,102]. Apparently, the advantage of being capable of reacting instantaneously to changing environmental conditions is more important for the organism than saving energy by inducing fermentation when it is needed. On the other hand the excretion of low-molecular organic compounds is of great importance for structure and functioning of the ecosystem since it will provide substrates for growth of other microorganisms (e.g. sulfate-reducing bacteria in marine microbial mats [118]). It is evident that the 
subject of regulation of fermentation in cyanobacteria deserves more attention.

There is no doubt that the energy yield of fermentation is low compared to phototrophic or respiratory metabolism and therefore it was generally assumed that fermentation in cyanobacteria would probably only be sufficient to cover maintenance requirements. However, a number of observations are not in agreement with this assumption. Species $M$. aeruginosa and $M$. chthonoplastes showed different rates of fermentation depending on the amount of storage carbohydrate in the cell. A higher rate of fermentation allows a higher rate of ATP production. Since it is not likely that maintenance requirements are different in cultures with low or high glycogen content it is evident that the additional ATP production can be used for non-maintenance purposes. Moreover, $O$. limosa was capable of maintaining the high-energy-requiring process of nitrogen fixation under anoxic conditions in the dark. Carbon and redox balances indicated that in high glycogen cultures some carbon must have been re-fixed, apparently at the expense of the ATP produced in addition of maintenance requirement. Maintenance requirements in cyanobacteria appeared to be extremely low but were in the same order of magnitude as the theoretical value which was calculated for E. coli.

Nothing is known about the intracellular levels of the adenylate and pyridine nucleotide pools during dark anoxic incubations of cyanobacteria capable of fermentation. In Synechococcus sp. an abrupt change of concentrations of ATP and NADPH occurs when the culture is transferred from the light to the dark under aerobic conditions. The ATP concentration returns to the light level within 15-20 $\mathrm{min}$ in the dark, whereas this was not the case with NADPH [119]. This was taken as evidence for an efficient dark energy generation in this organism. However, in $S y$ nechococcus $\mathrm{sp}$. this energy generation was shown to be dependent on oxygen [120]. It would be very interesting to carry out comparable studies with cyanobacteria capable of fermentation.

Sulfur appeared to be the only electron acceptor that is used during dark metabolism in many of the cyanobacteria tested. In most cases it must be concluded that it was unlikely that sulfur respiration occurred. The advantage of sulfur reduction was mainly the possibility of a higher production of acetate which would yield additional ATP. An exception was probably $O$. limnetica but calculations showed that the energy yield of sulfur respiration was only slightly higher as compared to homolactic acid fermentation.

The property of fermentation is essential for those cyanobacteria that in their natural environment are exposed to anoxic conditions in the dark. Species that did not possess this capacity died and lysed within $2-3 \mathrm{~h}$ after exposure to dark anoxic conditions (L.J. Stal, unpublished results). Dark anaerobic metabolism expands the metabolic versatility of cyanobacteria and also makes possible their ecological success. Moreover, the excretion of fermentation products is essential for the structure and functioning of ecosystems such as microbial mats in which photosynthesis by cyanobacteria is the driving force [121,122].

\section{Acknowledgments}

The comments of two anonymous reviewers on an earlier version of the paper are gratefully acknowledged.

\section{Appendix}

Estimation of the ATP production in Oscillatoria agardhii required for maintenance

According to Gons and Mur [123] the light-limited growth of phototrophic microorganisms is described by:

$\frac{1}{x} \cdot \frac{d E}{d t} \cdot c=\mu_{\mathrm{g}}+\mu_{\mathrm{m}}$

where $x$ is the biomass $(\mathrm{J}), d E / d t$ the light uptake rate $\left(\mathrm{J} \mathrm{h}^{-1}\right), \mu_{\mathrm{g}}$ the specific growth rate $\left(\mathrm{h}^{-1}\right), \mu_{\mathrm{m}}$ the specific maintenance rate $\left(\mathrm{h}^{-1}\right)$, and $c$ the efficiency of the conversion of light energy into biomass. Eq. A1 can be arranged to:

$\mu_{\mathrm{g}}=q_{\mathrm{E}^{*}} c-\mu_{\mathrm{m}}$ 
in which $q_{\mathrm{E}}$ is the biomass-specific light energy uptake $\left(\mathrm{h}^{-1}\right)$ :

$q_{\mathrm{E}}=\frac{1}{x} \cdot \frac{d E}{d t}$

For the lower specific growth rates a plot of $\mu_{\mathrm{g}}$ versus $q_{\mathrm{E}}$ results in a straight line with slope $c$. The intercept with the abscissa corresponds to the specific light energy uptake required for maintenance, $q_{\mathrm{E}}^{\mathrm{m}}$, and extrapolation to the ordinate provides an estimate for $-\mu_{\mathrm{m}}$. The relation between $q_{\mathrm{E}}^{\mathrm{m}}$ and the corresponding rate of ATP production $q_{\mathrm{ATP}}^{\mathrm{m}}$ is given by:

$q_{\mathrm{ATP}}^{\mathrm{m}}=q_{\mathrm{E}}^{\mathrm{m}} \cdot \frac{\Phi_{\mathrm{ATP}}}{\varepsilon}$

[124] in which $q_{\mathrm{ATP}}^{\mathrm{m}}$ is expressed in mol ATP per hour per joule biomass, $\varepsilon$ is the energy per mol of light quanta $\left(\mathrm{J} \mathrm{mol}^{-1}\right)$, and $\Phi_{A T P}$ the photochemical efficiency of ATP formed per light quanta absorbed. In order to express $q_{\mathrm{ATP}}^{\mathrm{m}}$ in mol ATP per min per mg biomass, the value obtained with Eq. A4 has to be multiplied by the heat of combustion of biomass $Q$ $\left(\mathrm{J} \mathrm{mg}^{-1}\right)$ and divided by 60 :

$q_{\mathrm{ATP}}^{\mathrm{m}}=\frac{q_{\mathrm{E}}^{\mathrm{m}} \cdot Q \cdot \Phi_{\mathrm{ATP}}}{\varepsilon \cdot 60}$

The specific maintenance light energy uptake $q_{\mathrm{E}}^{\mathrm{m}}$ is not constant but increases with incident light intensity [125]. For the cyanobacterium $O$. agardhii $q_{\mathrm{E}}^{\mathrm{m}}$ values ranged from $0.004 \mathrm{~h}^{-1}$ at $0.5 \mathrm{~W} \mathrm{~m}^{-2}$ to $0.02 \mathrm{~h}^{-1}$ at $40 \mathrm{~W} \mathrm{~m}^{-2}$ [126]. Assuming that the data obtained with the lowest light intensity result in the most accurate estimation of $q_{\mathrm{E}}^{\mathrm{m}}$, we have used the $q_{\mathrm{E}}^{\mathrm{m}}$ value of $0.004 \mathrm{~h}^{-1}$ to calculate $q_{\mathrm{ATP}}^{\mathrm{m}}$. The energy of the photosynthetically active radiation $(400-700 \mathrm{~nm})$ of the lamps used to grow $O$. agardhii was $2.19 \times 10^{5} \mathrm{~J}$ (mol of quanta) $)^{-1}$ [124]. The heat of combustion of $O$. agardhii cells grown under lightlimiting continuous culture was $22.1 \mathrm{~J} \mathrm{mg}^{-1}$ [5].

In oxygenic photosynthesis, eight quanta are minimally required to release one molecule of $\mathrm{O}_{2}$ from water and to transport four electrons over the thylakoid membrane to ferredoxin. As a result of water splitting and electron transport, eight protons accumulate inside the thylakoid lumen forming a proton motive force. ATP is generated by $\mathrm{H}^{+}$efflux from the thylakoid lumen through ATP synthetase, one
ATP being formed for every $3 \mathrm{H}^{+}$. Thus, $1 \mathrm{~mol}$ of ATP is formed per $3 \mathrm{~mol}$ of light quanta absorbed: $\Phi_{\mathrm{ATP}}=\frac{1}{3}$.

Substituting the above values in Eq. A5 gives:

$$
\begin{aligned}
& q_{\mathrm{ATP}}^{\mathrm{m}}=\frac{0.004 \cdot 22.1}{2.19 \times 10^{5} \cdot 60} \cdot \frac{1}{3}= \\
& 2 \times 10^{-9} \mathrm{~mol} \mathrm{ATP} \mathrm{min}^{-1}(\mathrm{mg} \text { dry weight })^{-1}
\end{aligned}
$$

Since the protein content of biomass is $55 \%$ [6], this value corresponds to a $q_{\mathrm{ATP}}^{\mathrm{m}}$ of approximately 4 nmol ATP $\min ^{-1}$ (mg protein $)^{-1}$ during growth at a light intensity of $0.5 \mathrm{~W} \mathrm{~m}^{-2}$.

\section{References}

[1] Smith, A.J. (1982) Modes of cyanobacterial carbon metabolism. In: The Biology of Cyanobacteria (Carr, N.G. and Whitton, B.A., Eds.), pp. 47-85. Blackwell Scientific, Oxford.

[2] Bergman, B., Gallon, J.R., Rai, A.N. and Stal, L.J. (1997) $\mathrm{N}_{2}$ fixation by non-heterocystous cyanobacteria. FEMS Microbiol. Rev. 19, 139-185.

[3] Bergman, B., Johansson, C. and Söderbäck, E. (1992) The Nostoc-Gunnera symbiosis. New Phytol. 122, 379-400.

[4] Matthijs, H.C.P. and Lubberding, H.J. (1988) Dark respiration in cyanobacteria. In: Biochemistry of the Algae and $\mathrm{Cy}-$ anobacteria (Rogers, L.J. and Gallon, J.R., Eds), pp. 131-145. Clarendon Press, Oxford.

[5] Van Liere, L., Mur, L.R., Gibson, C.E. and Herdman, M. (1979) Growth and physiology of Oscillatoria agardhii Gomont cultivated in continuous culture with a light-dark cycle. Arch. Microbiol. 123, 315-318.

[6] Post, A.F., Loogman, J.G. and Mur, L.R. (1985) Regulation of growth and photosynthesis by Oscillatoria agardhii grown with a light/dark cycle. FEMS Microbiol. Ecol. 31, 97-102.

[7] Post, A.F., Loogman, J.G. and Mur, L.R. (1986) Photosynthesis, carbon flows and growth of Oscillatoria agardhii Gomont in environments with a periodic supply of light. J. Gen. Microbiol. 132, 2129-2136.

[8] Tandeau de Marsac, N. and Houmard, J. (1994) Adaptation of cyanobacteria to environmental stimuli: new steps towards molecular mechanisms. FEMS Microbiol. Rev. 104, 119-190.

[9] Saku, J. and Adhikary, S.P. (1982) Heterotrophic growth and pigment composition of four filamentous blue-green algae. Arch. Hydrobiol. (Suppl.) 63, 189-200.

[10] De Philippis, R., Margheri, M.C. and Vincenzini, M. (1996) Fermentation in symbiotic and free-living cyanobacteria. Arch. Hydrobiol. Algol. Stud. 83, 459-468.

[11] Wolk, C.P. and Shaffer, P.W. (1976) Heterotrophic microand macro-cultures of a nitrogen-fixing cyanobacterium. Arch. Microbiol. 102, 123-127.

[12] Watanabe, A. and Yamamoto, Y. (1967) Heterotrophic nitro- 
gen fixation by the blue-green alga Anabaenopsis circularis. Nature 214, 738.

[13] Rippka, R. (1972) Photoheterotrophy and chemoheterotrophy among unicellular blue-green algae. Arch. Mikrobiol. 87, 9398 .

[14] Khoja, T.M. and Whitton, B.A. (1971) Heterotrophic growth of blue-green algae. Arch. Mikrobiol. 79, 280-282.

[15] Khoja, T.H. and Whitton, B.A. (1975) Heterotrophic growth of filamentous blue-green algae. Br. Phycol. J. 10, 139-148.

[16] Fay, P. (1965) Heterotrophy and nitrogen fixation in Chlorogloea fritschii. J. Gen. Microbiol. 39, 11-20.

[17] Miller, J.S. and Allen, M.M. (1972) Carbon utilization patterns in the heterotrophic blue-green alga Chlorogloea fritschii. Arch. Microbiol. 86, 1-12.

[18] Hutson, K.G., Rogers, L.J., Haslett, B.G. and Boulter, D. (1980) Ferredoxins from two cyanobacteria capable of heterotrophic growth in the dark. FEMS Microbiol. Lett. 7, 279284.

[19] Smith, A.J. and Hoare, D.S. (1977) Specialist phototrophs, lithotrophs, and methylotrophs: a unity among a diversity of procaryotes? Bacteriol. Rev. 41, 419-448.

[20] Joset-Espardellier, F., Astier, C., Evans, E.H. and Carr, N.G. (1978) Cyanobacteria grown under photoautotrophic, photoheterotrophic and heterotrophic regimes: sugar metabolism and carbon dioxide fixation. FEMS Microbiol. Lett. 4, 261264.

[21] Diakoff, S. and Scheibe, J. (1975) Cultivation in the dark of the blue-green alga Fremyella diplosiphon: a photoreversible effect of green and red light on growth rate. Physiol. Plant. 34, 125-128.

[22] Moezelaar, R. and Stal, L.J. (1994) Fermentation in the unicellular cyanobacterium Microcystis PCC7806. Arch. Microbiol. 162, 63-69.

[23] Harder, R. (1917) Ernahrungsphysiologische Untersuchungen an Cyanophyceen, hauptsächlich dem endophytischen Nostoc punctiforme. Z. Bot. 9, 145.

[24] Hoare, D.S., Ingram, L.O., Thurston, E.L. and Walkup, R. (1971) Dark heterotrophic growth of an endophytic bluegreen alga. Arch. Mikrobiol. 78, 310-321.

[25] Bottomley, P.J. and Van Baalen, C. (1978) Characteristics of heterotrophic growth in the blue-green alga Nostoc sp. strain Mac. J. Gen. Microbiol. 107, 309-318.

[26] Bottomley, P.J. and Van Baalen, C. (1978) Dark hexose metabolism by photoautotrophically and heterotrophically grown cells of the blue-green alga (cyanobacterium) Nostoc sp. strain Mac. J. Bacteriol. 135, 888-894.

[27] Beauclerk, A.D. and Smith, A.J. (1978) Transport of D-glucose and 3-O-methyl-D-glucose in the cyanobacteria Aphanocapsa 6714 and Nostoc strain Mac. Eur. J. Biochem. 82, 187197.

[28] Richardson, L.L. and Castenholz, R.W. (1987) Enhanced survival of the cyanobacterium Oscillatoria terebriformis in darkness under anaerobic conditions. Appl. Environ. Microbiol. 53, 2151-2158.

[29] Ingram, L.O., Calder, J.A., Van Baalen, C., Plucker, F.E. and Parker, P.L. (1973) Role of reduced exogenous organic compounds in the physiology of the blue-green bacteria (algae): photoheterotrophic growth of a heterotrophic blue-green bacterium. J. Bacteriol. 114, 695-700.

[30] Smoker, J.A. and Barnum, S.R. (1990) Nitrogen fixation activity of a filamentous, nonheterocystous cyanobacterium in the presence and absence of exogenous, organic substrates. Arch. Microbiol. 153, 417-421.

[31] Raboy, B., Padan, E. and Shilo, M. (1976) Heterotrophic capacities of Plectonema boryanum. Arch. Microbiol. 110, 77-85.

[32] White, A.W. and Shilo, M. (1975) Heterotrophic growth of the filamentous blue-green alga Plectonema boryanum. Arch. Microbiol. 102, 123-127.

[33] Marquez, F.J., Sasaki, K., Kakizono, T., Nishio, N. and Nagai, S. (1993) Growth characteristics of Spirulina platensis in mixotrophic and heterotrophic conditions. J. Ferment. Bioeng. 76, 408-410.

[34] Marquez, F.J., Nishio, N. and Nagai, S. (1995) Enhancement of biomass and pigment production during growth of Spirulina platensis in mixotrophic culture. J. Chem. Tech. Biotechnol. 62, 159-164.

[35] Anderson, S.L. and Mcintosh, L. (1991) Light-activated heterotrophic growth of the cyanobacterium Synechocystis sp. strain PCC-6803 - A blue-light-requiring process. J. Bacteriol. 173, 2761-2767.

[36] Kiyohara, T.Y., Fujita, Y., Hattori, A. and Watanabe, A. (1960) Heterotrophic culture of a blue-green alga, Tolypothrix tenuis I. J. Gen. Appl. Microbiol. 6, 176-182.

[37] Moezelaar, R. and Stal, L.J. (1997) A comparison of fermentation in the cyanobacterium Microcystis PCC7806 grown under a light-dark cycle and continuous light. Eur. J. Phycol. (in press).

[38] Gorrell, T.E. and Uffen, R.L. (1977) Fermentative metabolism of pyruvate by Rhodospirillum rubrum after anaerobic growth in darkness. J. Bacteriol. 131, 533-543.

[39] Schön, G. and Voelskow, H. (1976) Pyruvate fermentation in Rhodospirillum rubrum and after transfer from aerobic to anaerobic conditions in the dark. Arch. Microbiol. 107, 87-92.

[40] Yen, H.C. and Marrs, B. (1977) Growth of Rhodopseudomonas capsulata under anaerobic dark conditions with dimethyl sulfoxide. Arch. Biochem. Biophys. 181, 411-418.

[41] Madigan, M.T. and Gest, H. (1978) Growth of a photosynthetic bacterium anaerobically in darkness, supported by 'oxidant-dependent' sugar fermentation. Arch. Microbiol. 117, 119-122.

[42] Van Gemerden, H. (1968) On the ATP generation by Chromatium in darkness. Arch. Mikrobiol. 64, 118-124.

[43] Cohen, Y., Jørgensen, B.B., Revsbech, N.P. and Poplawski, R. (1986) Adaptation to hydrogen sulfide of oxygenic and anoxygenic photosynthesis among cyanobacteria. Appl. Environ. Microbiol. 51, 398-407.

[44] Oren, A. and Shilo, M. (1979) Anaerobic heterotrophic dark metabolism in the cyanobacterium Oscillatoria limnetica: sulfur respiration and lactate fermentation. Arch. Microbiol. 122, $77-84$.

[45] Gfeller, R.P. and Gibbs, M. (1984) Fermentative metabolism of Chlamydomonas reinhardii. I. Photoassimilation of acetate. Plant Physiol. 82, 160-166. 
[46] Kreuzberg, K. and Martin, W. (1984) Oscillatory starch degradation and fermentation in the green alga Chlamydomonas reinhardii. Biochim. Biophys. Acta 799, 291-297.

[47] Cohen, Y., Krumbein, W.E., Goldberg, M. and Shilo, M. (1977) Solar Lake (Sinai). 1. Physical and chemical limnology. Limnol. Oceanogr. 22, 597-608.

[48] Cohen, Y., Krumbein, W.E. and Shilo, M. (1977) Solar Lake (Sinai). 2. Distribution of photosynthetic microorganisms and primary production. Limnol. Oceanogr. 22, 609-620.

[49] Cohen, Y., Padan, E. and Shilo, M. (1975) Facultative anoxygenic photosynthesis in the cyanobacterium Oscillatoria limnetica. J. Bacteriol. 123, 855-861.

[50] Stal, L.J. (1995) Physiological ecology of cyanobacteria in microbial mats and other communities. New Phytol. 131, 132.

[51] Revsbech, N.P., Jørgensen, B.B., Blackburn, T.H. and Cohen, Y. (1983) Microelectrode studies of the photosynthesis and $\mathrm{O}_{2}, \mathrm{H}_{2} \mathrm{~S}$ and $\mathrm{pH}$ profiles of a microbial mat. Limnol. Oceanogr. 28, 1062-1074.

[52] Reynolds, C.S. (1987) Cyanobacterial waterblooms. Adv. Bot. Res. 13, 67-143.

[53] Fallon, R.D. and Brock, T.D. (1981) Overwintering of Microcystis in Lake Mendota. Freshwater Biol. 11, 217-226.

[54] Reynolds, C.S., Jaworski, G.H.M., Cmiech, H.A. and Leedale, G.F. (1981) On the annual cycle of the blue-green alga Microcystis aeruginosa Kütz Emend Elenkin. Phil. Trans. R. Soc. Lond. Biol. 293, 419-477.

[55] Reynolds, C.S. and Walsby, A.E. (1975) Waterblooms. Biol. Rev. 50, 437-481.

[56] Ibelings, B.W. and Mur, L.R. (1992) Microprofiles of photosynthesis and oxygen concentration in Microcystis scums. FEMS Microbiol. Ecol. 86, 195-203.

[57] Stewart, W.D.P., Rowell, P. and Rai, A.N. (1983) Cyanobacteria-eukaryotic plant symbioses. Ann. Microbiol. (Paris) 134 B, 205-228.

[58] Tredici, M.R., Margheri, M.C., Giovannetti, L., De Philippis, R. and Vincenzini, M. (1988) Heterotrophic metabolism and diazotrophic growth of Nostoc sp. from Cycas circinalis. Plant Soil 110, 199-206.

[59] Stal, L.J. and Krumbein, W.E. (1986) Metabolism of cyanobacteria in anaerobic marine sediments. Deuxième colloque international de bactériologie marine, Actes de Colloques Vol. 3, pp. 301-309. Gerbam, Ifremer, Brest.

[60] Van der Oost, J., Bulthuis, B.A., Feitz, S., Krab, K. and Kraayenhof, R. (1989) Fermentation metabolism of the unicellular cyanobacterium Cyanothece PCC 7822. Arch. Microbiol. 152, 415-419.

[61] Moezelaar, R., Bijvank, S.M. and Stal, L.J. (1996) Fermentation and sulfur reduction in the mat-building cyanobacterium Microcoleus chthonoplastes. Appl. Environ. Microbiol. 62, 1752-1758.

[62] Margheri, M.C. and Allotta, G. (1993) Homoacetic fermentation in the cyanobacterium Nostoc sp. strain Cc from Cycas circinalis. FEMS Microbiol. Lett. 111, 213-218.

[63] Heyer H., Stal, L.J. and Krumbein, W.E. (1989) Simultaneous heterolactic and acetate fermentation in the marine cyanobac- terium Oscillatoria limosa incubated anaerobically in the dark. Arch. Microbiol. 151, 558-564.

[64] Heyer, H. and Krumbein, W.E. (1991) Excretion of fermentation products in dark and anaerobically incubated cyanobacteria. Arch. Microbiol. 155, 284-287.

[65] Aoyama, K., Uemura, I., Miyake, J. and Asada, Y. (1997) Fermentative metabolism to produce hydrogen gas and organic compounds in a cyanobacterium, Spirulina platensis. J. Ferment. Bioeng. 83, 17-20.

[66] Stal, L.J. and Reed, R.H. (1987) Low-molecular mass carbohydrate accumulation in cyanobacteria from a marine microbial mat in response to salt. FEMS Microbiol. Ecol. 45, 305312 .

[67] Reed, R.H. and Stewart, W.D.P. (1988) The responses of cyanobacteria to salt stress. In: Biochemistry of Algae and Cyanobacteria (Rogers, L.J. and Gallon, J.R., Eds.), pp. 217-231. Clarendon Press, Oxford.

[68] Stal, L.J. (1992) Poly(hydroxyalkanoate) in cyanobacteria: an overview. FEMS Microbiol. Rev. 103, 169-180.

[69] Simon, R.D. (1987) Inclusion bodies in the cyanobacteria: cyanophycin, polyphosphate, polyhedral bodies. In: The $\mathrm{Cy}-$ anobacteria (Fay, P. and Van Baalen, C., Eds.), pp. 199-225. Elsevier, Amsterdam.

[70] Stal, L.J., Heyer, H., Bekker, B., Villbrandt, M. and Krumbein, W.E. (1989) Aerobic-anaerobic metabolism in the cyanobacterium Oscillatoria limosa. In: Microbial Mats. Physiological Ecology of Benthic Microbial Communities (Cohen, Y. and Rosenberg, E., Eds.), pp. 255-276. ASM, Washington, DC.

[71] Van der Oost, J. (1989) The Hydrogen Metabolism of the Unicellular Cyanobacterium Cyanothece PCC7822. PhD Thesis, Vrije Universiteit, Amsterdam.

[72] Heise, R., Muller, V. and Gottschalk, G. (1989) Sodium dependence of acetate formation by the acetogenic bacterium Acetobacterium woodii. J. Bacteriol. 171, 5473-5478.

[73] Heyer, H. (1989) Der anaerobe Dunkelmetabolismus von $O s-$ cillatoria limosa. $\mathrm{PhD}$ Thesis, Universität Oldenburg, Oldenburg.

[74] Stal, L.J., Bekker, S. and Meier, F. (1988) Hydrogenase activities in the marine nitrogen-fixing cyanobacterium Oscillatoria limosa. Abstr. VI Int. Symp. Phot. Prok. p. 21.

[75] Moezelaar, R., Teixeira de Mattos, M.J. and Stal, L.J. (1995) Lactate dehydrogenase in the cyanobacterium Microcystis PCC7806. FEMS Microbiol. Lett. 127, 47-50.

[76] Schaub, B.E.M. and Stal, L.J. (1996) Anaerobic reduction of iron and sulfur by the marine benthic cyanobacterium Microcoleus chthonoplastes. Abstr. 5th Eur. Mar. Microbiol. Symp. p. 46.

[77] Thauer, R.K., Jungermann, K. and Decker, K. (1977) Energy conservation in chemotrophic anaerobic bacteria. Bacteriol. Rev. 41, 100-180.

[78] Leach, C.K. and Carr, N.G. (1971) Pyruvate: ferredoxin oxidoreductase and its activation by ATP in the blue-green alga Anabaena variabilis. Biochim. Biophys. Acta 245, 165-174.

[79] Bothe, H., Falkenberg, B. and Nolteernsting, U. (1974) Properties and function of the pyruvate:ferredoxin oxidoreductase 
from the blue-green alga Anabaena cylindrica. Arch. Mikrobiol. 96, 291-304.

[80] Neuer, G. and Bothe, H. (1982) The pyruvate:ferredoxin oxidoreductase in heterocysts of the cyanobacterium Anabaena cylindrica. Biochim. Biophys. Acta 716, 358-365.

[81] Hallenbeck, P.C., Kochian, L.V. and Benemann, J.R.. (1981) Hydrogen evolution catalyzed by hydrogenase in cultures of cyanobacteria. Z. Naturforsch. 36C, 87-92.

[82] Houchins, J.P. and Burris, R.H.. (1981) Comparative characterization of two distinct hydrogenases from Anabaena sp. strain 7120. J. Bacteriol. 146, 215-221.

[83] Sanchez, J.J., Palleroni, N.J. and Doudoroff, M. (1975) Lactate dehydrogenases in cyanobacteria. Arch. Microbiol. 104, $57-65$.

[84] Garvie, E.I. (1980) Bacterial lactate dehydrogenases. Microbiol. Rev. 44, 106-139.

[85] Pearce, J. and Carr, N.G. (1967) The metabolism of acetate by the blue-green algae Anabaena variabilis and Anacystis nidulans. J. Gen. Microbiol. 49, 301-313.

[86] Pelroy, R.A., Rippka, R. and Stanier, R.Y. (1972) Metabolism of glucose by unicellular blue-green algae. Arch. Mikrobiol. 87, 303-322.

[87] Fewson, C.A., Al-Hafidh, M. and Gibbs, M. (1962) Role of aldolase in photosynthesis. I. Enzyme studies with photosynthetic organisms with special reference to blue-green algae. Plant Physiol. 37, 402-406.

[88] Pearce, J. and Carr, N.G. (1969) The incorporation and metabolism of glucose by Anabaena variabilis. J. Gen. Microbiol. 54, 451-462.

[89] Bishop, R.H. (1979) Regulatory characteristics of a fructose bisphosphatase from the blue-green bacterium Anacystis nidulans. Arch. Biochem. Biophys. 196, 295-300.

[90] Houchins, J.P. (1984) The physiology and biochemistry of hydrogen metabolism in cyanobacteria. Biochim. Biophys. Acta 768, 227-255.

[91] Howarth, D.C. and Codd, G.A. (1985) The uptake and production of molecular hydrogen by unicellular cyanobacteria. J. Gen. Microbiol. 131, 1561-1569.

[92] Asada, Y. and Kawamura, S. (1984) Hydrogen evolution by Microcystis aeruginosa in darkness. Agric. Biol. Chem. 48, 2595-2596.

[93] Asada, Y. and Kawamura, S. (1986) Screening for cyanobacteria that evolve molecular hydrogen under dark and anaerobic conditions. J. Ferment. Technol. 64, 553-556.

[94] Asada, Y., Kawamura, S. and Ho, K.-K. (1987) Hydrogenase from the unicellular cyanobacterium Microcystis aeruginosa. Phytochemistry 26, 637-640.

[95] Almon, H. and Böger, P. (1988) Hydrogen metabolism of the unicellular cyanobacterium Chroococcidiopsis thermalis ATCC29380. FEMS Microbiol. Lett. 49, 445-449.

[96] Serebriakova, L., Zorin, N.A. and Lindblad, P. (1994) Reversible hydrogenase in Anabaena variabilis ATCC29413. Presence and localization in non- $\mathrm{N}_{2}$-fixing cells. Arch. Microbiol. 161, 140-144.

[97] Sheridan, R.P. and Castenholz, R.W. (1968) Production of hydrogen sulphide by a thermophilic blue-green alga. Nature 217, 1063-1064.
[98] Sheridan, R.P. (1973) Hydrogen sulfide production by Synechococcus lividus. J. Phycol. 9, 437-445.

[99] Pfennig, N. and Biebl, H. (1976) Desulfuromonas acetoxidans gen.nov. and sp. nov., a new anaerobic, sulfur-reducing acetate-oxidizing bacterium. Arch. Microbiol. 110, 3-12.

[100] Stal, L.J. (1991) The sulfur metabolism of mat-building cyanobacteria in anoxic marine sediments. Kieler Meeresforsch. 8, 152-157.

[101] Mishra, D. and Schmidt, A. (1992) Regulation and partly purification of the ATP-sulfurylase from the cyanobacterium Synechococcus-6301. Z. Naturforsch. C47, 95-101.

[102] Stal, L.J. (1994) Microbial mats in coastal environments. In: Microbial Mats. Structure, Development and Environmental Significance (Stal, L.J. and Caumette, P., Eds.), NATO ASI Series, Vol. G35, pp. 21-32. Springer Verlag, Heidelberg.

[103] Van Bergeijk, S.A. and Stal, L.J. (1996) The role of oxygenic phototrophic microorganisms in production and conversion of dimethylsulfoniopropionate and dimethylsulfide in microbial mats. In: Biological and Environmental Chemistry of DMSP and Related Sulfonium Compounds (Kiene, R.P., Visscher, P.T., Keller, M.D. and Kirst, G.O., Eds.), pp. 369-379. Plenum, New York.

[104] Stewart, W.D.P., Fitzgerald, G.P. and Burris, R.H. (1968) Acetylene reduction by nitrogen-fixing blue-green algae. Arch. Mikrobiol. 62, 336-348.

[105] Stal, L.J. and Heyer, H. (1987) Dark anaerobic nitrogen fixation (acetylene reduction) in the cyanobacterium Oscillatoria sp. FEMS Microbiol. Ecol. 45, 227-232.

[106] Van Liere, L. and Mur, L.R.. (1979) Growth kinetics of Oscillatoria agardhii Gomont in continuous culture, limited in its growth by the light energy supply. J. Gen. Microbiol. $115,153-160$.

[107] Snoep, J.L. (1992) Regulation of Pyruvate Catabolism in Enterococcus faecalis. A Molecular Approach to Physiology. PhD Thesis, Universiteit van Amsterdam, Amsterdam.

[108] Stal, L.J. and Krumbein, W.E. (1985) Oxygen protection of nitrogenase in the aerobically nitrogen fixing nonheterocystous cyanobacterium Oscillatoria sp. Arch. Microbiol. 143, $72-76$.

[109] Russell, J.B. and Cook, G.M. (1995) Energetics of bacterial growth: Balance of anabolic and catabolic reactions. Microbiol. Rev. 59, 48-62.

[110] Ljones, T. (1979) Nitrogen fixation and bioenergetics: the role of ATP in nitrogenase catalysis. FEBS Lett. 98, 1-8.

[111] Konings, W.N., Lolkema, J.S. and Poolman, B. (1995) The generation of metabolic energy by solute transport. Arch. Microbiol. 164, 235-242.

[112] Moezelaar, R. (1995) Fermentation in the Cyanobacteria $M i$ crocystis aeruginosa and Microcoleus chthonoplastes. $\mathrm{PhD}$ Thesis, University of Amsterdam, Amsterdam.

[113] Atkinson, M.J. and Smith, S.V. (1983) C:N:P ratios of benthic marine plants. Limnol. Oceanogr. 28, 568-574.

[114] Coleman, J.R. and Colman, B. (1981) Inorganic carbon accumulation and photosynthesis in a blue-green alga as a function of external pH. Plant Physiol. 67, 917-921.

[115] Ehrlich, H.L. (1996) Geomicrobiology. Marcel Dekker, New York. 
[116] De Wit, R., van Boekel, W.H.M. and van Gemerden, H. (1988) Growth of the cyanobacterium Microcoleus chthonoplastes on sulfide. FEMS Microbiol. Ecol. 53, 203-209.

[117] Richardson, L.L. and Castenholz, R.W. (1987) Diel vertical movements of the cyanobacterium Oscillatoria terebriformis in a sulfide-rich hot spring microbial mat. Appl. Environ. Microbiol. 53, 2142-2150.

[118] Van Gemerden, H. (1993) Microbial mats: A joint venture. Mar. Geol. 113, 3-25.

[119] Ihlenfeldt, M.J.A. and Gibson, J. (1975) $\mathrm{CO}_{2}$ fixation and its regulation in Anacystis nidulans (Synechococcus). Arch. Microbiol. 102, 13-21.

[120] Biggins, J. (1969) Respiration in blue-green algae. J. Bacteriol. 99, 570-575.

[121] Anderson, K.L., Tayne, T.A. and Ward, D.M. (1987) Formation and fate of fermentation products in hot spring cyanobacterial mats. Appl. Environ. Microbiol. 53, 2343-2352.

[122] Nold, S.C. and Ward, D.M. (1996) Photosynthate partition- ing and fermentation in hot spring microbial mat communities. Appl. Environ. Microbiol. 62, 4598-4607.

[123] Gons, H.J. and Mur, L.R. (1975) An energy balance for algal populations in light-limiting conditions. Verh. Int. Verein. Limnol. 19, 2729-2733.

[124] Gons, H.J. (1977) On the Light-limited Growth of Scenedesmus protuberans Fritsch. Ecological and Physiological Aspects of the Energy Requirements for Growth and Maintenance of a Planktonic Green Alga. PhD Thesis, University of Amsterdam, Amsterdam.

[125] Gons, H.J. and Mur, L.R. (1980) Growth rate and light uptake rate in light-limited continuous cultures of Scenedesmus protuberans Fritsch. Arch. Microbiol. 125, 9-17.

[126] Van Liere, L. (1979) On Oscillatoria agardhii Gomont, Experimental Ecology and Physiology of a Nuisance Bloomforming Cyanobacterium. PhD Thesis, University of Amsterdam, Amsterdam. 